\title{
Processing and Properties of (Mo,Cr) Oxycarbides from MOCVD
}

\author{
Wen-Cheng J. Wei* and Ming-Hung Lot \\ Institute of Materials Science and Engineering, National Taiwan University, Taipei, 106 Taiwan, Republic \\ of China
}

\begin{abstract}
A review of the coating kinetics of molybdenum and chromium oxycarbides and a study on the properties of deposited films are reported. Molybdenum carbonyl, chromium carbonyl and their mixture were used to prepare coatings at temperatures between 170 and $450{ }^{\circ} \mathrm{C}$ on SS304 or SiC substrates by a process of metalorganic chemical vapor deposition (MOCVD). The processing parameters of the coatings, such as the evaporation of precursors, coating pressure and temperature, are discussed along with the coating rates, compositions and other microstructural information, so to reveal the kinetics of the coating process on two different substrates. In addition, the chemical composition, crystalline phases and microstructure of the coatings obtained in various conditions are presented with the evidence interpreted by various electron-microscopic and spectroscopic techniques, including XRD, EDS, EPMA and XPS. The dependence of some properties, such as hardness, adhesive strength and corrosive resistance of the coatings on SS 304, on their composition and the deposited phases, i.e. as a function of coating temperature and pressure, is reviewed. (C) 1998 John Wiley \& Sons, Ltd.
\end{abstract}

Appl. Organometal. Chem. 12, 201-220 (1998)

Keywords: MOCVD; molybdenum oxycarbide; chromium oxycarbide; coating; kinetics; microstructure

Received 28 December 1996; accepted 4 June 1997

\footnotetext{
* Correspondence to: Prof. W. J. Wei, Institute of Materials Science and Engineering, National Taiwan University, Taipei, 106 Taiwan, Republic of China.

$\dagger$ Current address: Prosperity Dielectrics Co. Ltd., Taiwan, Republic of China.

Contract/grant sponsor: National Science Council, Taiwan; Contract/grant number: NSC85-2216-E-002-019.
}

\section{INTRODUCTION}

Surface modification and characterization are two important issues of materials science and engineering, and have gained the attention of scientists for decades past. The improvement of surface coating technology and the establishment of knowledge on surface science are the keys to applying these technologies in various fields. Several successful cases of applications with surface modification have been reported. Superalloys with high-temperature ceramic coatings performs appropriately in an environment under extreme oxidation and corrosion conditions ${ }^{1,2}$. Some hard coatings, e.g. diamond films, on cutting tools are useful for wear resistance.

Lander $^{3}$ first reported the use of metal carbonyls as sources for coatings. These material systems containing metal compositions have a high melting temperature. The use of this technique was a major breakthrough for making monolithic refractory metal. The vapor of metal carbonyls was thermally pyrolyzed, then deposited on a substrate to form metal-related phases. Recently, a laser source was adopted and acted as a trigger mechanism for the deposition. ${ }^{4,5}$ The process is categorized as a laserinduced chemical vapor deposition (LICVD). This technique is attractive to the Integrated Circuit (IC) industry for preparing electronic devices and for repair and miniaturization of circuits. Electrically conductive materials, such as molybdenum or chromium, deposit on the designated area. However, the deposition area is limited by the diameter of a laser beam. Large-area deposition is difficult for LICVD, but not for thermo-induced coating processes, which may coat a wide range substrates at temperatures not higher than $400^{\circ} \mathrm{C}^{6,7}$.

Research work reported in the literature on chemical vapor deposition by thermal steps has established knowledge of the kinetics and reaction mechanisms of the process. The techniques for the determination of physical and chemical properties, such as crystalline structure, composition and mechanical strength, of the coated layer are well 
established. However, the coatings are not in thermal equilibrium; they change according to the variation of the deposit environment. The properties of the coating need to be characterized by better and modern analytical techniques, such as x-ray photo-electron spectroscopy (XPS) and high-resolution transmission electron microscopy (HRTEM), to resolve the mystery of the deposition reactions.

Some coating studies on molybdenum or chromium using similar methods have been reported. However, the effects of control factors on the coating process and control mechanism of the molybdenum carbonyl system are still unknown. The control factors, such as temperature, pressure and flow rate of carrier gases, revealed in the literature were somewhat diversified. For example, the pressure and temperature used by Ferguson et $a l .{ }^{8}$ were 0.3 to 0.35 Torr and $300{ }^{\circ} \mathrm{C}$; these were 0.076 Torr and $375^{\circ} \mathrm{C}$ by Kmetz et al. ${ }^{9}$ respectively. Moreover, the decomposition temperature of molybdenum carbonyl is reported to be as low as $150^{\circ} \mathrm{C}$. The coating behavior and morphology at coating temperatures lower than $300^{\circ} \mathrm{C}$ have never been studied. The control factors of the deposition process need to be studied systematically and the resulting knowledge needs to be assembled.

\section{PROCESS STEPS FOR MOLYBDENUM AND CHROMIUM CARBONYLS}

Metal-organic vapor deposition is one of the CVD processes. An atomic model of vapor-phase reaction and deposition is illustrated in Fig. 1 in which basically five consecutive reaction steps are taking place: evaporation, pyrolysis, diffusion, adsorption/ desorption on the surface and diffusion of the reaction products. Among these steps, pyrolysis and diffusion of $(\mathrm{Mo}, \mathrm{Cr})(\mathrm{CO})_{6}$ molecules may occur simultaneously. In fact, the surface reaction can be classified into three discrete steps-adsorption, surface diffusion and desorption of gas molecules-but no direct evidence has been presented in the literature. The rate-limiting steps of these reactions are categorized into either thermodynamic (evaporation/pyrolysis), mass transport (diffusion) or kinetic. ${ }^{10}$

\subsection{Evaporation of $\left.\mathrm{Mo}_{(\mathrm{CO}}\right)_{6}$ and $\mathrm{Cr}(\mathrm{CO})_{6}$}

The evaporation rate $\left(R_{v}\right)$ of a solid phase was formulated $^{1}$ as follows:

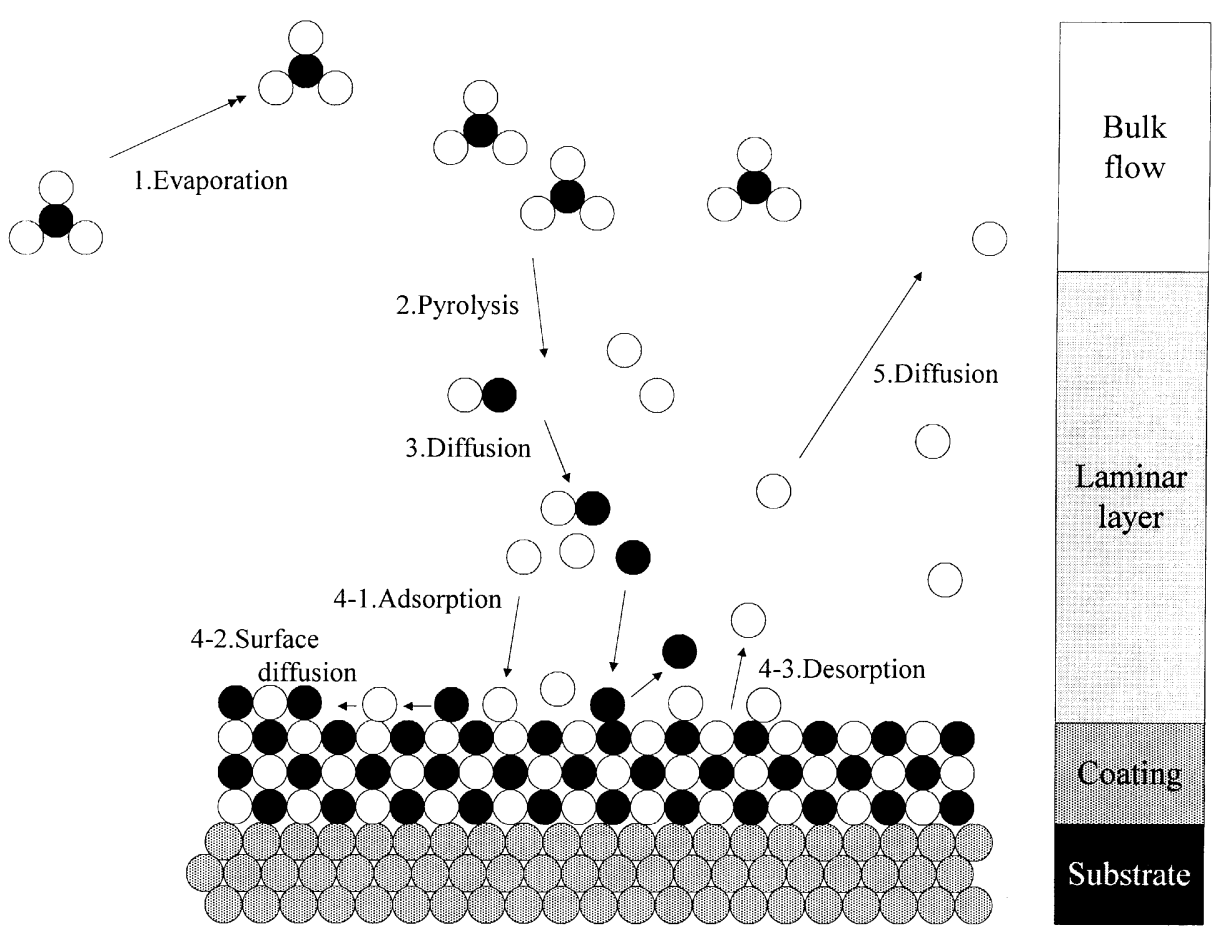

Figure 1 Atomic model of the five consecutive reaction steps of metal-organic chemical vapor deposition. 


$$
R_{\mathrm{v}}=\alpha_{\mathrm{v}}\left(\frac{m}{2 \pi k T}\right)^{1 / 2}\left(P^{*}-P\right)
$$

where $m$ is the molecular weight, $\alpha_{v}$ is a constant related to the purity and surface area of a solid, $k$ is the Planck constant, $T$ is the absolute temperature and $P^{*}$ and $P$ are the saturation pressure and the gas pressure of a specific gas species. The larger the pressure difference $\left(P^{*}-P\right)$, the greater the evaporation rate.

The saturation pressure of two carbonyls was measured $^{3}$ as a function of temperature:

$$
\begin{aligned}
& \text { For } \mathrm{Cr}(\mathrm{CO})_{6}: \log P^{*}=11.832-3755.2 / T \\
& \text { For } \mathrm{Mo}(\mathrm{CO})_{6} ; \log P^{*}=11.174-3561.3 / T
\end{aligned}
$$

However, the evaporation of a carbonyl mixture is determined not only by the pressure difference of the species, but also by the states of solid solution and the constant $\alpha_{\nu}$.

The relationship between $\alpha_{v}$ and the evaporation rate $R_{\mathrm{e}}$ of a powder bed can be obtained from the measurement of the evaporation flux $\left(J_{\mathrm{d}}\right)$, as shown in Eqn [4].

$$
J_{\mathrm{d}}=\frac{R_{\mathrm{e}}}{A}=\frac{\Delta W * A_{\mathrm{f}}}{A M \Delta t}
$$

where $A$ is the cross-section area of the gas flow outlet, $\Delta W$ is the weight difference for the powder bed before and after testing. $\Delta t$ is time interval of the measurement, $M$ is the average molecular weight and $A_{\mathrm{f}}$ is Avogadro's number. If the vacuum of the evaporation system is held at 1.0 Torr at room temperature, the flux of a molybdenum carbonyl powder bed is $1.13 \times 10^{15}$ molecules $\mathrm{s}^{-1} \mathrm{~cm}^{-3}$

\subsection{Pyrolysis of metallic carbonyls}

The dissociation of metallic carbonyls begins at temperatures ranging from 150 to $155^{\circ} \mathrm{C}$. The carbonyl gas molecules are then pyrolyzed thermally as the gas stream flows into the reaction chamber with temperatures above $175^{\circ} \mathrm{C}$. The researchers ${ }^{11-18}$ have determined the dissociation kinetics and energies of pure Mo and $\mathrm{Cr}$ carbonyls and their admixtures. The pyrolysis occurs on the breaking of metal/(CO) bonds, and is classified as a first-order reaction. The controlling step of the reaction is the dissociation of the first or second $\mathrm{CO}$ for $\mathrm{Mo}(\mathrm{CO})_{6}$ or $\mathrm{Cr}(\mathrm{CO})_{6}$, respectively. The remaining $\mathrm{COs}$ are rapidly dissociated as the pyrolysis proceeds.

The reaction coefficient and activation energy of

(C) 1998 John Wiley \& Sons, Ltd.

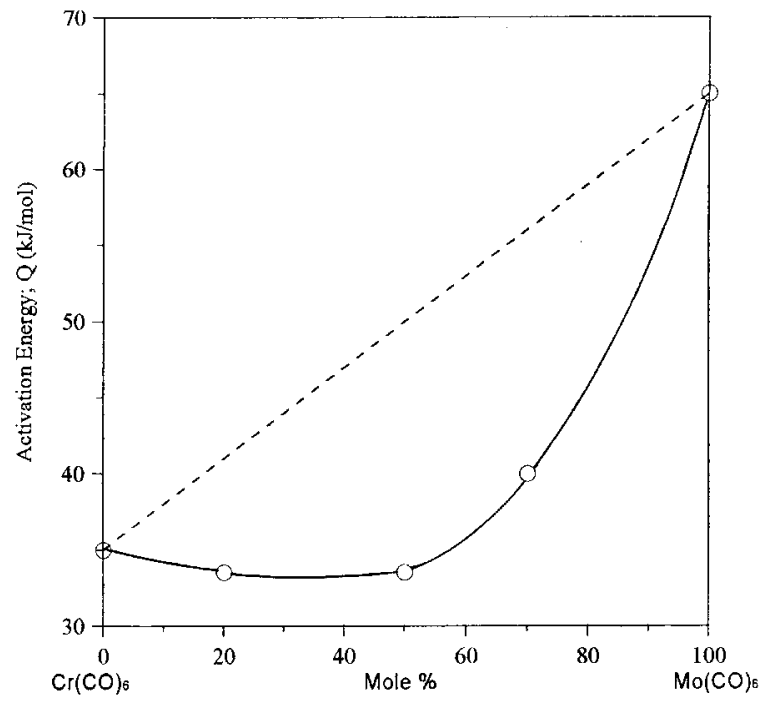

Figure 2 Activation energies of pyrolysis of chromium and molybdenum carbonyls and their admixture (adapted from Refs 14, 19).

each metallic carbonyl were determined by Baev. ${ }^{19}$ It is shown in Fig. 2 (broken line) that the admixtures of $\mathrm{Mo}(\mathrm{CO})_{6}$ and $\mathrm{Cr}(\mathrm{CO})_{6}$ have significantly lower activation energy values than predicted by the law of mixtures. It is postulated that chromium acts as a catalyst to activate molybdenum carbonyls to pyrolyze.

Due to the first-order reaction, the pyrolysis rate, $R_{\mathrm{p}}$, of a $(\mathrm{Mo}, \mathrm{Cr})$ carbonyl is

$$
R_{\mathrm{p}}=k_{\mathrm{t}}[\mathrm{C}]
$$

where $k_{t}$ is a reaction constant [C] is the concentration of reactant. The pyrolyzed products of carbonyls are metallic atoms and $\mathrm{CO}$ molecules. If $10 \mathrm{~mol} \% \mathrm{Cr}$,Mo carbonyl is selected as the source, $k_{0}$ and $Q$ are 50 and $53.2 \mathrm{~kJ} \mathrm{~mol}^{-1}$, respectively. ${ }^{19}$ These two constants are taken into account, and the pyrolysis temperatures are set between 175 and $450{ }^{\circ} \mathrm{C}$. Then the pyrolysis rate per unit volume given by the Arrhenius equation is between $1.16 \times 10^{12}\left(175^{\circ} \mathrm{C}\right)$ and $2.32 \times 10^{13}$ molecules $\mathrm{s}^{-1} \mathrm{~cm}^{-3}\left(450{ }^{\circ} \mathrm{C}\right)$ in the $(\mathrm{Mo}, \mathrm{Cr})$ coating system. In other words, the flux of the reaction equals the pyrolysis rate in a unit of molecular density per unit time:

$$
\begin{aligned}
& J_{\mathrm{p}}=R_{\mathrm{p}}= 1.16 \times 10^{12} \text { to } 2.32 \times 10^{13} \text { molecules } \\
& \mathrm{s}^{-1} \mathrm{~cm}^{-3},\left(175 \text { to } 450{ }^{\circ} \mathrm{C}\right)
\end{aligned}
$$


The evaporation flux, $1.13 \times 10^{15}$ molecules $\mathrm{s}^{-1} \mathrm{~cm}^{-3}$, calculated in Section 2.1 is two orders higher than the pyrolysis rate per unit volume. Therefore, evaporation of carbonyls cannot be the controlling step in the present case. Later, the measurement of coating kinetics of $(\mathrm{Mo}, \mathrm{Cr})$ carbonyls will prove that the pyrolysis is not the controlling step either.

\subsection{Vapor diffusion}

Gas flowing in a reaction chamber is treated as a laminar flow. The transport of vapor molecules from one layer to another of gas flow occurs by diffusion. ${ }^{7}$ In a coating system, the leading edge of a substrate blocks the nearest gas layer, called a boundary layer. The surface of the substrate exhibits a friction effect on the boundary layer. The speed of gas flow, concentration of gas species and temperature distribution of the boundary layer may be different from the above laminar flow. The transport of gas reactants and products through the boundary layer is the major issue for vapor diffusion.

At a given coating temperature, 170 to $450{ }^{\circ} \mathrm{C}$, and a constant pressure of 1.0 Torr, the free-path distance $(l)$ of molybdenum is estimated from Eqn [7]:

$$
1=\frac{k T}{\sqrt{2} \pi d^{2} p}
$$

where $k$ is Boltzmann's constant, $T$ is the absolute temperature, $d$ is the collision diameter of a gas molecule and $p$ is the gas pressure. The value of the free-path distance, $l$, is in the order of $10^{-7}$ to $10^{-6}$ $\mathrm{m}$, which is much smaller than the dimensions of the coating chamber (free space between the tube wall and the surface of the substrate). An ordinary diffusion is expected. Therefore, the diffusivity of

Table 1 Calculated diffusivity of molybdenum and chromium vapor species at various temperatures

\begin{tabular}{lccc}
\hline $\begin{array}{l}\text { Temperature } T \\
\left({ }^{\circ} \mathrm{C}\right)\end{array}$ & $\begin{array}{c}\text { Pressure } P \\
\text { (Torr) }\end{array}$ & $\begin{array}{c}\text { Diffusion } \\
\text { coefficient, } \\
D_{\mathrm{Cr}}\left(\mathrm{cm}^{2-1} \mathrm{~s}\right)\end{array}$ & $\begin{array}{c}\text { Diffusion } \\
\text { coefficient, } \\
D_{\mathrm{Mo}}\left(\mathrm{cm}^{2-1} \mathrm{~s}\right)\end{array}$ \\
\hline 450 & 1 & 851 & 668 \\
400 & 1 & 750 & 589 \\
350 & 1 & 655 & 514 \\
300 & 1 & 566 & 444 \\
275 & 1 & 522 & 410 \\
225 & 1 & 442 & 347 \\
175 & 1 & 367 & 288 \\
\hline
\end{tabular}

(C) 1998 John Wiley \& Sons, Ltd. the two species, molybdenum and chromium can be calculated from Eqn [8]:

$$
D_{\mathrm{AB}}=\frac{\left(1 \times 10^{-3}\right) T^{1.75}}{P\left(V_{\mathrm{A}}^{1 / 3}+V_{\mathrm{B}}^{1 / 3}\right)} \sqrt{\frac{1}{M_{\mathrm{A}}}+\frac{1}{M_{\mathrm{B}}}}
$$

where $M_{i}$ is the molecular weight of diffusion species $i$, e.g. A or B, and $V_{i}$ is its diffusive volume and can be obtained from the table reported by Fuller $e t$ al $^{20}$ The diffusion species include $\mathrm{Mo}, \mathrm{Cr}$ and $\mathrm{CO}$. Although the concentration of $\mathrm{CO}$ is six times higher than that of $\mathrm{Cr}$ or Mo, the diffusion of these two metallic species is the rate-limiting factor. Table 1 shows that the diffusion coefficient of $\mathrm{Cr}, D_{\mathrm{Cr}}$, is $27 \%$ higher than $D_{\mathrm{Mo}}$ in the specified temperature region.

Stringfellow ${ }^{7}$ studied the boundary effect of vapor transport near the substrate surface. The diffusion flux $\left(J_{\mathrm{d}}\right)$ through the boundary layer of a tube reactor can be formulated as

$$
J_{\mathrm{d}}=\frac{2.68 D C_{0}}{h \exp \left(-2.84 D z / h^{2} v_{0}\right)}
$$

where $C_{0}$ is the concentration of reactant at the inlet, $h$ and $z$ are the geometric constants of the reaction tube, representing the vertical and horizontal distances respectively between substrate surface and vapor inlet, and $v_{0}$ is the volume of the gases. By substituting the known reaction conditions (checking the experimental device in Section 3.2) in the above equation, the flux is nearly infinitely large. This means that the volume of reactants supplied to substrate is larger than is needed for the deposition reaction. As a consequence, the diffusion of $\mathrm{Cr}$ and Mo carbonyls in the present case cannot be a controlling step for the coating process.

\subsection{Surface reaction and transport}

A major difference between surface control and mass-transport control is the concentration distribution of reactants in the boundary layer. The former shows a constant concentration through the boundary layer, but there is a deficiency in the concentration of reactants in the mass-transport case which results in distinctive coating properties. Better uniformity in chemical composition and thickness is often found in the former case; the latter is greatly affected by surface roughness and results in a concentration variation near the surface. Moreover, nucleation and growth of new phase(s) are not only controlled by the reaction on the surface, but also by the states of surface conditions.

Appl. Organometal. Chem. 12, 201-220 (1998) 
Lo and Wei reported ${ }^{21}$ that there were more than four crystalline phases formed in the reaction conditions (175 to $450{ }^{\circ} \mathrm{C}$ coating temperatures and 1.0 Torr vapor pressure). Coating situations from the viewpoint of thermodynamics or kinetics are far more complex than those reported in the literature.

For an interfacial reaction, which is dependent on the gas pressure, the ideal growth rate or the maximum deposition rate can be estimated from the Hertz-Knudsen equation: [10]

$$
J_{\mathrm{c}}=\frac{P}{\sqrt{2 \pi M k T}}
$$

where $J_{\mathrm{c}}$ is the flux (in units of molecules $\mathrm{m}^{-2} \mathrm{~s}^{-1}$ of the molecules striking the surface of the coated layer, $P$ is the partial pressure of the controlled species (in $\mathrm{Pa}$ ) and $M$ is the molecular weight (in $\mathrm{kg}$ $\mathrm{mol}^{-1}$ ).

However, Eqn [10] does not consider the fact that only a fraction of the sites on the substrate are available and only the striking molecules with suitable activation energy can be adsorbed and bonded to the solid coating layer. In other words, a striking coefficient in the reference condition with an activation energy $\Delta H_{\mathrm{c}}$ should be considered corresponding to the combined process of adsorption and bonding of Mo and $\mathrm{CO}$ molecules. If this is introduced, the expression can be modified to

$$
J_{\mathrm{c}}=\frac{P}{\sqrt{2 \pi M k T}} \cdot A_{\mathrm{s}} \exp \left(-\Delta H_{\mathrm{c}} / R T\right)
$$

where $A_{\mathrm{s}}$ is a function of the substrate orientation, the surface structure and the state of the available site. As a consequence, the plot of $J_{\mathrm{c}}$ is dependent on gas pressure, and increases with the temperature if the coating process is controlled by the surface reaction.

\section{PREPARATION OF MOLYBDENUM AND CHROMIUM CARBONYL COATINGS}

\subsection{Preparation of substrates}

Stainless steel 304 substrates were sliced from a plate with a thickness of $1 \mathrm{~mm}$ to a square shape, $5 \mathrm{~mm} \times 5 \mathrm{~mm}$. The thermal gradient between the two surfaces of the substrate is minimized by reducing the thickness of the substrate. SS304 substrates were ground, then polished with alumina slurry $(0.3 \mu \mathrm{m})$ to yield smooth surfaces, one surface being for the deposition of film, the other for the attachment of the thermocouple. After polishing, the thickness of the substrates was less than $0.8 \mathrm{~mm}$.

Monolithic $\mathrm{SiC}$ was prepared by pressureless sintering from 059(S) powder (supplied by Superior Graphite Co., USA) with 10 vol\% $\mathrm{Al}_{2} \mathrm{O}_{3}$ as a sintering aid. The $\mathrm{SiC}$, as analyzed by $\mathrm{XRD}$, consisted of mostly $\alpha$-SiC with very minor $\mathrm{Al}_{2} \mathrm{O}_{3}$ and $\mathrm{Al}_{4} \mathrm{SiC}_{4}$ phases. It exhibited the typical microstructure of a pressureless-sintered $\mathrm{SiC}$ with polygonal porosity. The porosity of the $\mathrm{SiC}$ block is $8-10 \%$, which was consistent with the result measured by Archimedes' method.

The preparation of $\mathrm{SiC}$ substrates followed similar steps as for SS304. Thin SiC substrates were sliced from the $\alpha$-SiC block in a square shape with a thickness less than $200 \mu \mathrm{m}$. These SiC substrates were then ground and polished to obtain one smooth surface using $1 \mu \mathrm{m}$ diamond paste. After polishing, the thickness of SiC was generally $100 \mu \mathrm{m}$. Polished substrates were cleaned thoroughly several times with acetone in an ultrasonic bath. In the last step before coating, the substrates were put into a vacuum vessel pumped to a pressure of 0.01 Torr and left overnight.

\subsection{Coating operation}

Observation of the continuity and uniformity of molybdenum coatings under various conditions was recently reported by Lo. ${ }^{22}$ Both continuity and uniformity of the deposition of molybdenum carbonyl powder by evacuation at room temperature is better than by heating at $1 \mathrm{~atm}$. The evaporation and coating system, as shown in Fig. 3 used in the following sections is operated in vacuum conditions $(P<3$ torr).

Pure carbonyls or a mixture of molybdenum and chromium hexacarbonyls $\mathrm{Mo}(\mathrm{CO})_{6}$ and $\mathrm{Cr}(\mathrm{CO})_{6}$ (Strem Chemicals Co., MA, USA), was put in a source chamber and carried by $\mathrm{N}_{2}$ gas $(99.9 \%$ pure) at a flow rate of $6 \mathrm{ml} \mathrm{min.-1}$ The mass fraction of chromium hexacarbonyl in the mixture was 0.10 (about $12 \%$ as a molar ratio). Coating was conducted in a hot-wall reactor. The temperature distribution, the position of the hot zone and placement of the stainless steel substrate along the reaction chamber were carefully determined. The carbonyl vapor flowed into one side of the reaction chamber (tube) while the other side of the reaction chamber was connected to two outlets, one for an absolute-pressure gauge with a variable-capacitance sensor (MSK Baratron, type 122A), and the 


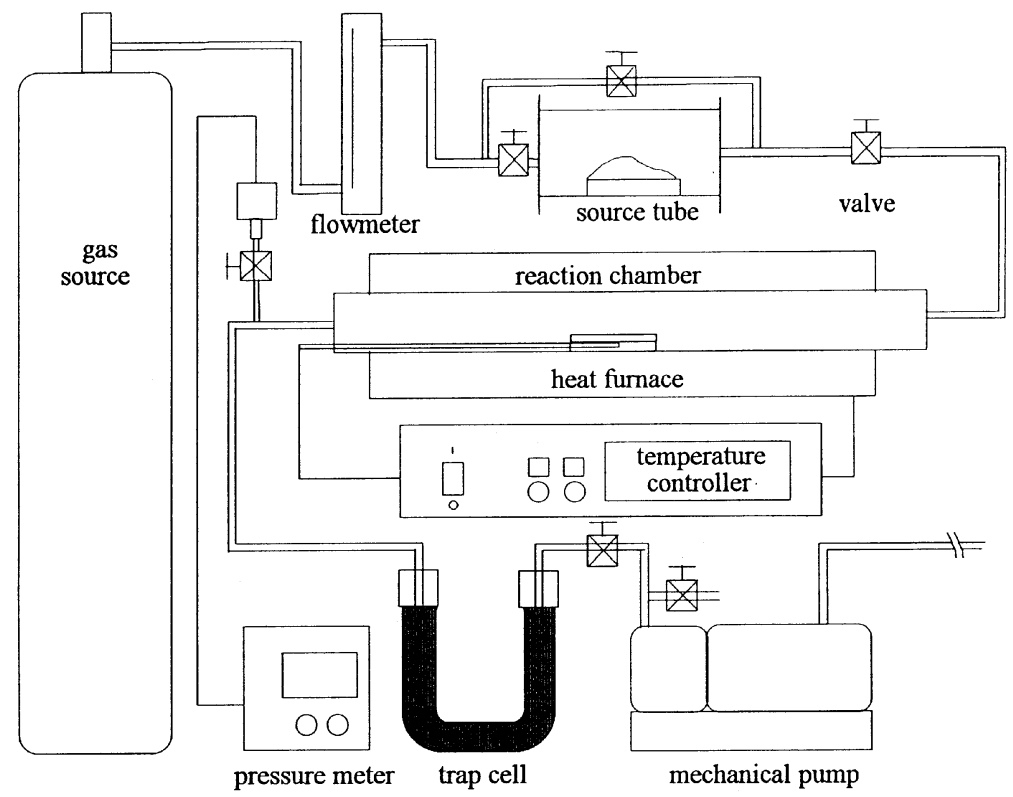

Figure 3 Schematic diagram of the coating equipment used in this research.

other for a rotary pump. The chamber was first emptied to less than $10^{-3}$ torr before introducing the carbonyls. When the coating temperature was reached, a pressure from 0.2 to 3.0 Torr was maintained by adjusting the valves between the flowmeter and the pumping system. Coating generally lasted for $10 \mathrm{~h}$ in two series of conditions. In the first, the coating pressure was changed from 0.025 to 2.5 Torr, but a constant temperature of $400{ }^{\circ} \mathrm{C}$ was maintained. In the other condition the coating temperature changed from 175 to $450{ }^{\circ} \mathrm{C}$, but a pressure of 1.0 Torr was maintained.

\subsection{Characterization}

The coating rate was estimated by measurement of the weight gain divided by surface area of the substrate and coating time. The morphology and thickness of the films were examined and measured directly with a scanning electron microscope (SEM, Philips 515, Holland). Crystalline phases were identified with an X-ray diffractometer (XRD, Philips PW1729, Holland).

Only the depositions at three different processing temperatures, which were representative of low$\left(225^{\circ} \mathrm{C}\right)$, medium- $\left(350^{\circ} \mathrm{C}\right)$ and high- $\left(450{ }^{\circ} \mathrm{C}\right)$ temperature regions, were characterized by the following spectroscopic techniques. The details of the microstructure of the coatings on SS304 were investigated by TEM and HRTEM (100CXII and 4000EX, JEOL Co., Japan). An X-ray photoelectron spectroscope (XPS, Perkin-Elmer, PHI, ESCA-5400, USA) was used for semiquantitative chemical analysis which was operated with $\mathrm{Ta}_{2} \mathrm{O}_{5}$ as a reference material. A multiple testing of the XPS on the skin-layer of the coating was performed with milling by an $\mathrm{Ar}^{+}$ion up to a depth of $42 \mathrm{~nm}$. The composition profiles across the thickness of the coatings were determined by electron probe $\mathrm{x}$-ray microanalyser (EPMA) (JXA-8600, JEOL Co., Japan) which was operated at $15 \mathrm{keV}$ with an electron probe size of $1 \mu \mathrm{m}$ and a current of $1 \times 10^{-7} \mathrm{~A}$. The corrosion resistance of the samples was determined by a potentiostat (Potentiostat/Galvanostat, Model 273A, USA). The corrosion current densities of the depositions at the three different processing temperatures $\left(225^{\circ} \mathrm{C}, 350^{\circ} \mathrm{C}\right.$ and $450{ }^{\circ} \mathrm{C}$ ) were determined by the Tafel method from the potentiodynamic scan curves. ${ }^{23}$

\section{COATING KINETICS}

\subsection{Coating rate at constant pressure}

$\mathrm{Lo}^{22}$ reported that the fast nucleation rate of 


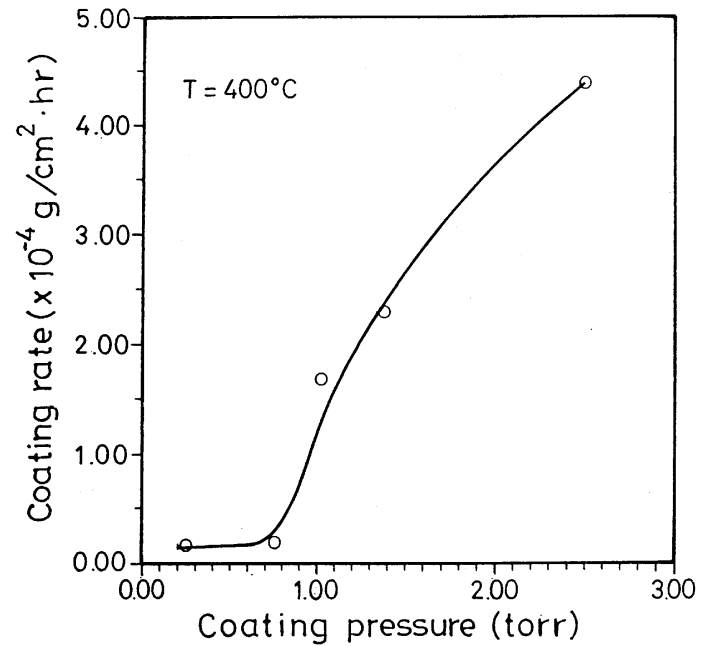

Figure 4 Coating rate of (Mo,Cr) oxycarbide on SS304 as a function of coating pressure at constant temperature $\left(400^{\circ} \mathrm{C}\right)$.

$\mathrm{Mo}_{2} \mathrm{C}_{x} \mathrm{O}_{y}$ deposition reaches a critical vapor pressure between 0.067 and 0.01 Torr. Figure 4 shows the coating rate plotted against coating pressure at a constant temperature of $400{ }^{\circ} \mathrm{C}$. For a coating pressure below 0.9 Torr the coating rate is totally independent of pressure, whereas in the pressure range 0.9 Torr the coating rate increases dramatically with coating pressure. The 'lowpressure region' and 'high-pressure region' are classified as the conditions which are operated at pressures lower and higher than 0.9 Torr, respectively.

The coating rate increases as the pressure increases in the high-pressure region. Because the pyrolysis of molybdenum carbonyl will increase the molar number, from 1 to $1+x$, of the gases in the system, for instance.

$$
\mathrm{Mo}(\mathrm{CO})_{x}(\mathrm{~g}) \leftrightarrow \mathrm{Mo}(\mathrm{g})+x \mathrm{CO}(\mathrm{g})
$$

higher pressure does not favor the pyrolysis reaction moving rightward. Besides, the diffusion is inversely proportional to coating pressure, as indicated in Eqn [8]. This implies that the pyrolysis and diffusion of the coating reactions are not the controlling mechanisms.

The flux, $J_{c}$ in Eqn [11], of Mo or Cr molecules striking the surface of the coated layer is proportional to the partial pressure of molybdenum vapor at constant temperature $\left(400^{\circ} \mathrm{C}\right)$ while the orientation and surface structure of the substrate are constant. However, the slope of the curve above 0.9 Torr in Fig. 4 deviates from a linear relation- ship. This is possibly due to the effect of dilution by $\mathrm{N}_{2}$ gas; the fraction of the $\mathrm{N}_{2}$ gas in the total gas mixture increases as the total pressure increases, but the absolute partial pressure of molybdenum does not increase proportionally with the coating pressure.

\subsection{Coating in vacuum conditions}

The dependence of coating rate on the processing temperature is treated as a thermally activated process. The activation energy $\left(Q_{\mathrm{c}}\right)$ is obtained from the slope of the fitting line,

$$
R_{\mathrm{c}}=R_{0} * \exp \left(-Q_{\mathrm{c}} / R T\right)
$$

Figure 5 shows plots of the coating rate of $\mathrm{Mo}(\mathrm{CO})_{6}$ or $\mathrm{Cr}(\mathrm{CO})_{6}$ on $\mathrm{SS} 304$ as a function of coating temperature. These two pure carbonyls have different coating rates and temperature ranges. The activation energies, derived from the slopes of the three fitting lines in Fig. 5 are $122.5 \mathrm{~kJ}$ mol, ${ }^{-1}$ $-68.3 \mathrm{~kJ} \mathrm{~mol}^{-1}$ and $49.1 \mathrm{~kJ} \mathrm{~mol}^{-1}$ Unlike the activation energies, 65 or $30 \mathrm{~kJ} \mathrm{~mol},{ }^{-1}$ of the pyrolysis reaction of $\mathrm{Mo}(\mathrm{CO})_{6}$ or $\mathrm{Cr}(\mathrm{CO})_{6}$, the coating cannot be controlled by the pyrolysis reaction.

Rickerby and Matthews ${ }^{1}$ proposed two Arrhenius' plots for endothermic and exothermic CVD

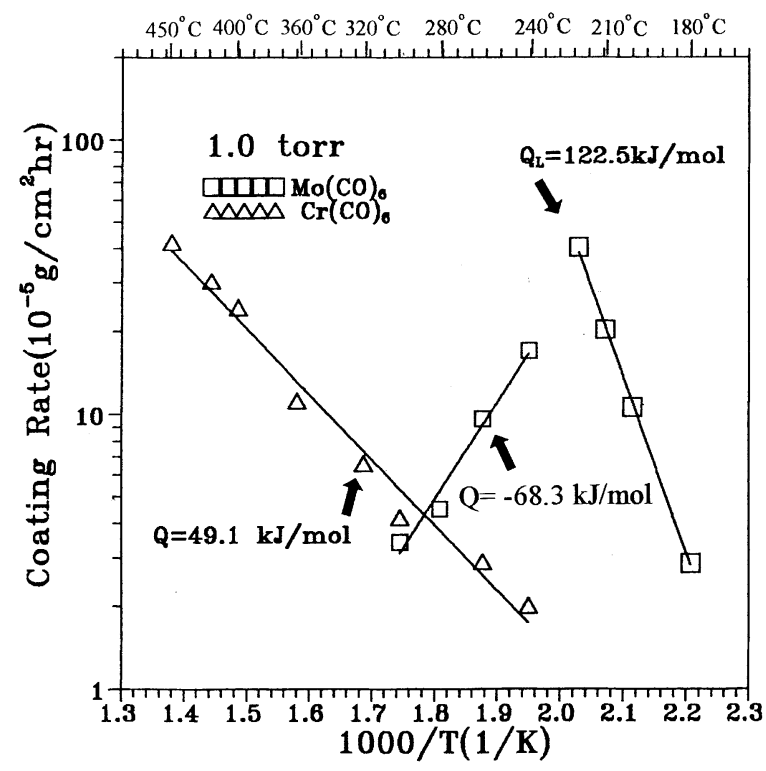

Figure 5 Coating rate on SS304 from the deposition of either $\mathrm{Mo}(\mathrm{CO})_{6}$ or $\mathrm{Cr}(\mathrm{CO})_{6}$ as a function of reciprocal temperature at a constant pressure of 1.0 torr.

Appl. Organometal. Chem. 12, 201-220 (1998) 
processes. The deposition rate plotted against the reciprocal of temperature has two or three regions which are controlled by various reaction mechanisms. For endothermic reactions, surface reaction shows a positive activation energy (negative slope), and controls the deposition at a low temperature. However, at higher temperatures, the controlling mechanism changes to mass transport with a lower activation energy, which is generally below $20 \mathrm{~kJ} \mathrm{~mol}^{-1}$. For exothermic reactions, the dependence of the deposition in the lower temperature region is similar to exothermic reactions: the deposition rate increases as the temperature increases, then changes to a diffusion control region at higher temperature. The major difference between exothermic and endothermic reactions is in the region of high temperature, in which the rate is again controlled by surface reactions. The decrease in the rate as the temperature increases in the high-temperature region is interpreted either as: (1) retardation of the desorption of products from the surface by the thermal effect, or (2) attainment of uniform nucleation of the surface. ${ }^{24}$ But the results are not conclusive.

The results in Fig. 5 show that the coating kinetics of $\mathrm{Mo}(\mathrm{CO})_{6}$ and $\mathrm{Cr}(\mathrm{CO})_{6}$ within the range $175-450{ }^{\circ} \mathrm{C}$ reveal only part of the rate dependence. The mass-transport-controlled region is missing in Fig. 5. This is consistent with the statement in Section 2.3 that the diffusion flux in the boundary layer nearly reaches infinity. The limiting step of the depositions of $\operatorname{Mo}(\mathrm{CO})_{6}$ and $\operatorname{Cr}(\mathrm{CO})_{6}$ is the surface reaction. But the former deposition shows two stages of rate dependence changing at $230^{\circ} \mathrm{C}$, the latter shows only one stage.

Taking $\mathrm{Mo}_{2} \mathrm{C}_{0.7} \mathrm{O}_{0.7}$ as the composition of the coatings, we have estimated the coating rate constant, i.e. coating flux $\left(J_{\mathrm{c}}\right)$, of Mo molecules from the measured coating rate (in units of $\mathrm{g} \mathrm{cm}^{-2}$ $\mathrm{h}^{-1}$ ). Four sets of the coating fluxes (data points of $310^{\circ} \mathrm{C}$ to $240{ }^{\circ} \mathrm{C}$ in Fig. 5) and coating temperatures at constant pressure were taken into account. The activation energy $\Delta H_{\mathrm{c}}$ of the adsorption and bonding was obtained from Eqn [11] to be $-65.5 \mathrm{~kJ} \mathrm{~mol}^{-1}$. Since the adsorption and bonding of gas molecules to form a condensed phase of $\mathrm{Mo}_{2} \mathrm{C}_{0.7} \mathrm{O}_{0.7}$ is an exothermic process, the value of the activation energy, $\Delta H_{\mathrm{c}}$, is negative and merely equals the summation of these energies involving the condensation of gas molecules to a solid phase and the bonding between the molecules.

If the temperature dependence of the reaction step is described by Eqn [13], from the slope of the fitted line between 310 and $240{ }^{\circ} \mathrm{C}$ in Fig. 5 the

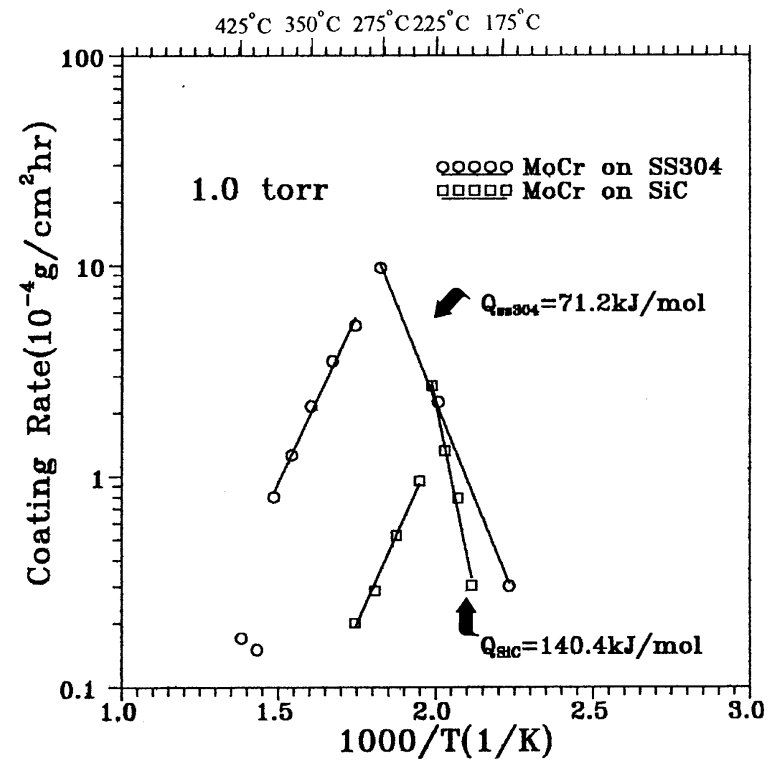

Figure 6 Coating rate of carbonyl mixture on SS304 and SiC versus the reciprocal of coating temperature at a constant pressure of 1.0 torr.

activation energy of the deposition reaction is $Q_{\mathrm{c}}=-68.3 \mathrm{~kJ} \mathrm{~mol}^{-1}$. The physical meaning of $Q_{\mathrm{c}}$ energy is different from that of $\Delta H_{\mathrm{c}}$, i.e. the activation energy of the condensation and bonding, since $Q_{\mathrm{c}}$ represents the whole process, including the impinging action in addition to the bonding of the molecules. That is,

$$
Q_{\mathrm{c}}=\Delta H_{\mathrm{s}}+\Delta H_{c}
$$

$\Delta H_{\mathrm{s}}$ is the reaction energy of the impingement on the substrate, and therefore is $2.8 \mathrm{~kJ} \mathrm{~mol}^{-1}$.

Figure 6 shows the coating rates of $(\mathrm{Mo}, \mathrm{Cr})$ carbonyl on SS304 or SiC substrates plotted against coating temperature. The activation energy of the coatings in the low-temperature region is higher for deposition on $\mathrm{SiC}$, i.e. $140.4 \mathrm{~kJ} \mathrm{~mol}^{-1}$, than on $\mathrm{SS} 304$, i.e. $71.2 \mathrm{~kJ} \mathrm{~mol}^{-1}$. It is noted that the rates and activation energies of the mixture of $(\mathrm{Mo}, \mathrm{Cr})$ carbonyls are different from those of pure carbonyls. The coating rate of the admixture of carbonyls on both substrates is about one order less than that of pure molybdenum carbonyl. The $\mathrm{SiC}$ substrate is contemplated as an inert material at the processing temperature, and SS304 can be a catalytic substrate for the deposition of molybdenum and chromiumrelated phases (in fact, $\mathrm{Mo}_{2} \mathrm{O}_{x} \mathrm{C}_{y}$ and $\mathrm{Cr}_{3} \mathrm{C}_{2}$ phases). The influence of coating kinetics on various substrates, which we consider to be the 
major evidence of a surface-reaction-controlled step, agrees with the previous suggestion that the surface reactions are the controlling step in this temperature region. However, the activation energies of the coating on SS304 or SiC in the higher-temperature region are nearly equal, $c a$ $-62 \mathrm{~kJ} \mathrm{~mol}^{-1}$, which is believed to be different from the activation energy $\left(-68.3 \mathrm{~kJ} \mathrm{~mol}^{-1}\right)$ of the coating from pure $\mathrm{Mo}(\mathrm{CO})_{6}$ (cf. Fig. 5).

In the higher-temperature region, the coating steps, such as impingement, condensation and bonding of $\mathrm{Mo}, \mathrm{Cr}$ and $\mathrm{CO}$ species on the surface of the substrate, are taking place with consequences similar to those seen in the atomic arrangement on SS304 or SiC surfaces. But the coating rate on SS304 is about 10 times higher than on SiC. The coating may be enhanced by the chromium and nickel elements present in stainless steel. Chromium and nickel metallic particles are reported ${ }^{18}$ with a catalytic effort on gas-phase reaction. The faster rate of the coating on SS304 is believed to be due to higher nucleation and growth kinetics which are enhanced by heterogeneous nucleation. The microstructure of the coating on SS304 or SiC which will be revealed below in the Section 5.2, shows the surfaces of the coatings to be of different roughnesses. The morphology (roughness) of the surfaces implies a consequence of nucleation and growth on the substrates.

Since it has been indicated that the controlling mechanism of the coating of $(\mathrm{Mo}, \mathrm{Cr})$ carbonyls is surface reaction, the results in Fig. 6 strongly suggest that there is a switching of the dominating reaction and depositing products between the lowand medium-temperature regions; one transition is at $225^{\circ} \mathrm{C}$ for the coating on $\mathrm{SiC}$, the other is at $275^{\circ} \mathrm{C}$ for SS304. A lower rate of the exothermic reaction at higher temperature is compensated by the increase in the fraction of homogeneous nucleation, and the decrease in heterogeneous nucleation. Therefore, the catalytic effects of gaseous chromium and SS304 are the main reasons for the transition of the dependence of the coating rate on temperature, and on density, composition and deposited phases with the coating temperature. This also implies that the deposition rate of products from pure chromium gas molecules is slower than the products from the mixture of molybdenum and chromium.

\section{PROPERTIES OF COATINGS FROM MOLYBDENUM AND CHROMIUM CARBONYLS}

\subsection{Crystalline phases and composition}

Past work on surface coatings primarily used pure metal carbonyls as the sources for oxycarbide coatings. Table 1 shows a summary of the crystalline phases of the molybdenum and chromium carbonyl coatings. In the early reports, the coated films were characterized as a metal phase. ${ }^{4,25-27}$ The carbon and oxygen contents detected by those researchers were treated as impurities. Besides, the crystal structure of the 'metal' phase of the coatings is indexed to be a face-centered cubic (fcc) structure, which is not the body-centered cubic (bcc) structure of molybdenum and chromium at room temperature. ${ }^{4}$ However, it has also been pointed out by other researchers ${ }^{3,28}$ that the fcc structure of the deposited phase is similar to $\mathrm{Mo}_{2} \mathrm{C}$ (Fig. 7a) with the chemical composition falling between $\mathrm{Mo}_{2} \mathrm{C}_{0.7} \mathrm{O}_{0.6}$ and $\mathrm{Mo}_{2} \mathrm{C}_{0.6} \mathrm{O}_{0.5}{ }^{8}$
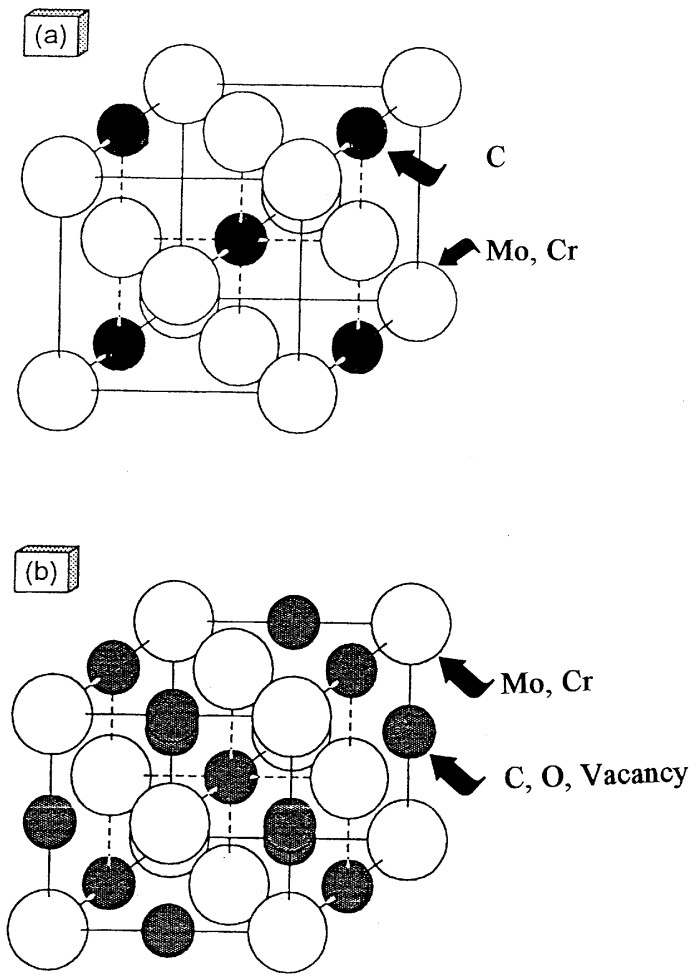

Figure 7 Schematic unit cell of (a) molybdenum carbide $\left(\mathrm{Mo}_{2} \mathrm{C}\right)$ and (b) molybdenum oxycarbide.

Appl. Organometal. Chem. 12, 201-220 (1998) 
The atomic structure of the $(\mathrm{Mo}, \mathrm{Cr})$ oxycarbide is, in fact, similar to the structure of rock salt, with $\mathrm{C}, \mathrm{O}$ or vacancies (of the anion sites) at the octahedral sites of its fcc structure constructed by (Mo,Cr) cations, as shown in Fig. 7(b). The carbon and oxygen ions are in a solid solution, and are different from the carbon in an $\mathrm{Mo}_{2} \mathrm{C}$ structure (Fig. 7a).

In addition to the $\mathrm{Mo}_{2} \mathrm{C}_{x} \mathrm{O}_{y}$ phase, other possible phases in the coatings are reported in Table 2; the reaction temperatures at which the $\mathrm{MoOC}, \mathrm{CrOC}$, $\mathrm{Cr}_{3} \mathrm{C}_{2}$ and $\mathrm{Cr}_{2} \mathrm{O}_{3}$ phases are formed are reported inconsistently in the various literature sources. XRD results from the coating from pure molybdenum or chromium carbonyl indicate mainly one phase, either $\mathrm{Mo}_{2} \mathrm{C}_{x} \mathrm{C}_{y}$ or $\mathrm{Cr}_{3} \mathrm{C}_{2}$ (a solid solution of oxygen and in very fine crystalline size), whereas the films obtained from the mixture of carbonyls but deposited on $\mathrm{SiC}$ are mainly an $\mathrm{Mo}_{2} \mathrm{O}_{x} \mathrm{O}_{y}$ phase combined with a minor $\mathrm{Cr}_{2} \mathrm{O}_{3}$ solid-solution phase. The $\mathrm{Mo}_{2} \mathrm{O}_{x} \mathrm{C}_{y}$ has a very fine crystalline size, as deduced from the width of the XRD peaks, when deposited below $240{ }^{\circ} \mathrm{C}$. The most complex phase combination of the coating is prepared on the surface of SS304. The phases appearing in the high- $\left(450{ }^{\circ} \mathrm{C}\right)$, medium- $\left(350^{\circ} \mathrm{C}\right)$, and low-temperature $\left(225^{\circ} \mathrm{C}\right)$ regions are quite unalike. The formation of each phase is closely related to the composition of the deposited films.

The composition data of other deposited films on SS304 from the carbonyl mixture analyzed by the XPS technique are shown in Fig. 8. The concentration variation of carbon and oxygen is limiting on the skin of the film in a thickness of $10-20 \mathrm{~nm}$; a higher carbon concentration is seen on the surface. ${ }^{22}$ The driving force concentrating carbon near the surface is still not well known, but in the graphite phase (the actual state of carbon near the surface), unbonding with oxygen might be responsible for the segregation of carbon on the surface and the formation of gaseous carbon monoxide and dioxide. $^{29-31}$

Underneath the skin, the concentrations of the elements molybdenum, chromium, carbon and oxygen are nearly constant as a function of coating temperature. Therefore, the compositions, which are believed to represent the entire thickness of the coatings, are plotted in Fig. 8. The composition profile in the figure reveals a $\mathrm{Cr} /$ cation ratio of $0.1: 1,0.76: 1$ or $0.98: 1$ (or $0.96: 1$ ), varying for the

Table 2 Summary of the reported phases in the coatings from either $\mathrm{Mo}(\mathrm{CO})_{6}$ or $\mathrm{Cr}(\mathrm{CO})_{6}$

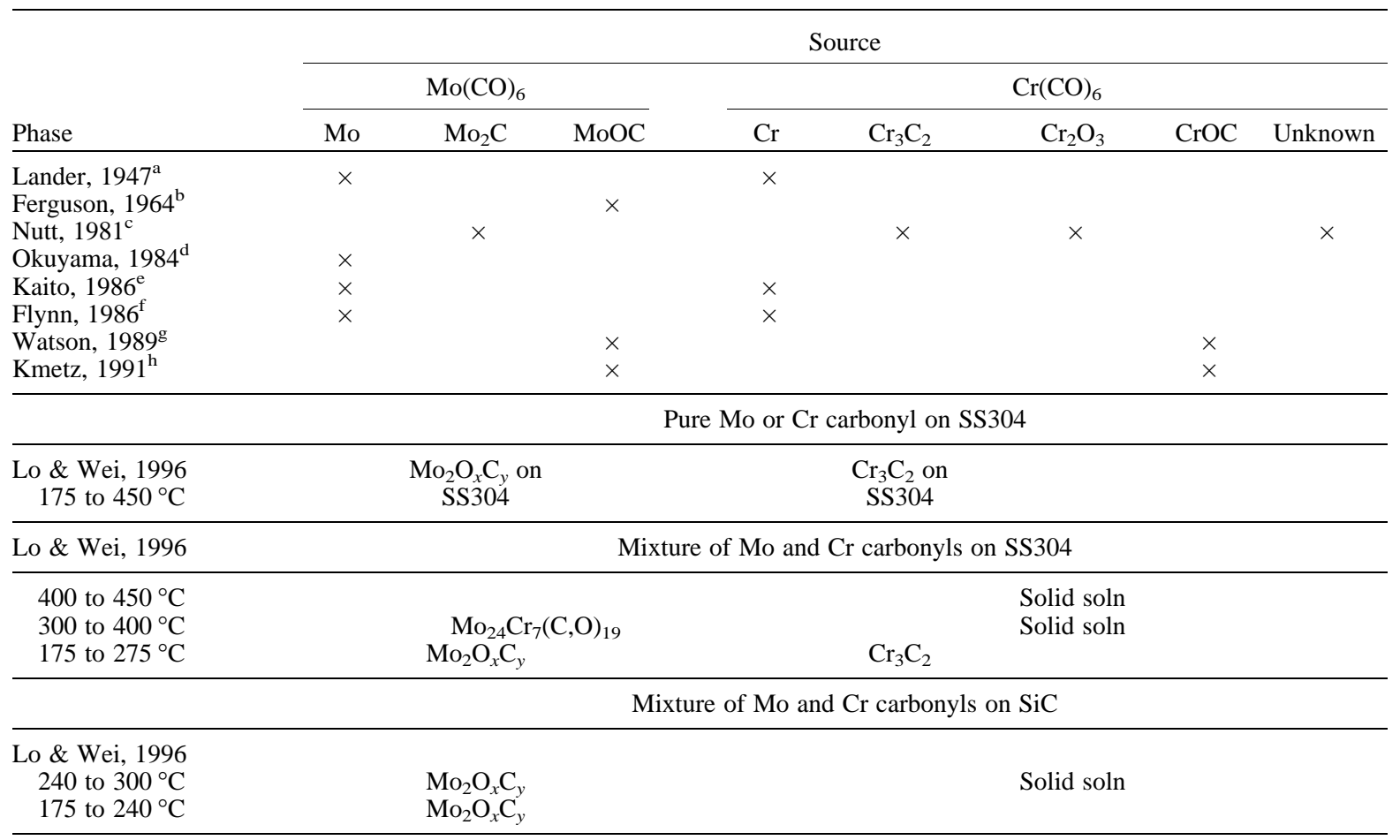

${ }^{\mathrm{a}}$ Ref. 3. ${ }^{\mathrm{b}}$ Ref. $8{ }^{\mathrm{c}}$ Ref. 28. ${ }^{\mathrm{d}}$ Ref. $4 .{ }^{\mathrm{e}}$ Ref. 25. ${ }^{\mathrm{f}}$ Ref. 26. ${ }^{\mathrm{g}}$ Ref. 31. ${ }^{\mathrm{h}}$ Ref. 9. ${ }^{\mathrm{i}}$ Ref. 36. 


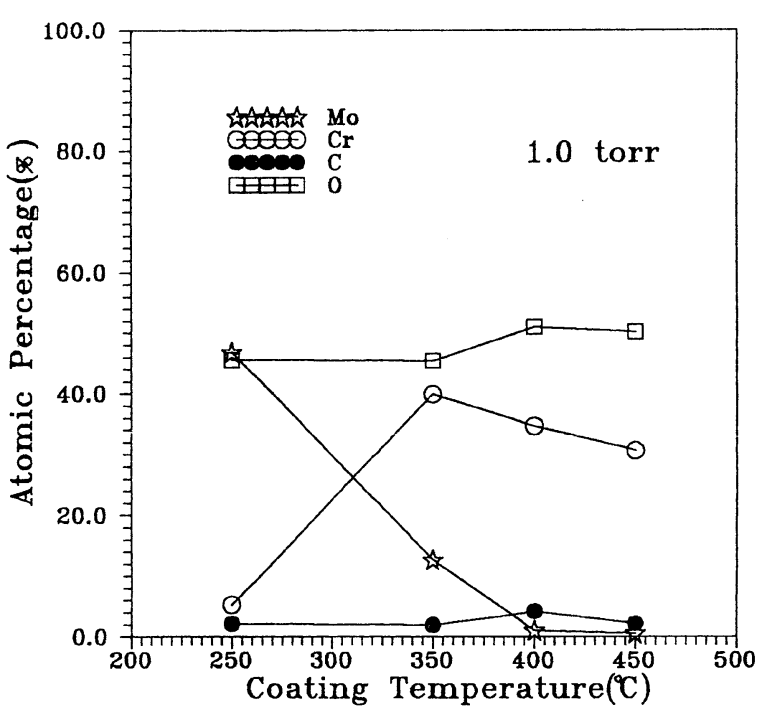

Figure 8 XPS analytical composition of the coatings on SS304 from carbonyl mixtures processed at specific temperatures and at P Torr pressure (adapted from Ref. ${ }^{21}$ ).

coatings prepared at low medium or high temperature.

No crystalline phases are found by XRD for the film from a carbonyl mixture deposited at $450{ }^{\circ} \mathrm{C}$ (high-temperature region), either because of their amorphous nature or because they were too thin to be detected by XRD. For the films obtained in this high-temperature region, the atomic ratio $\mathrm{Cr} / \mathrm{O}$ is $2: 3$ as analyzed by XPS in Fig. 8 . The phase composition of this film is, therefore, a $\mathrm{Cr}_{2} \mathrm{O}_{3}$ of which the theoretical density is $5.23 \mathrm{ml}^{-1}$; but a low density $\left(2.75 \pm 0.15 \mathrm{~g} \mathrm{ml}^{-1}\right)$ of the film has been measured and reported, ${ }^{21}$ and seems to unveil the porous character of the layers. The morphologies of the film shown by an SEM micrograph in Fig. 9(j) (below) does not clearly exhibit the porous character.

The elemental composition of the film coated with the hexacarbonyls at $350{ }^{\circ} \mathrm{C}$ (medium-temperature region) includes mainly $\mathrm{Cr}$ and $\mathrm{O}$, with minor proportions of Mo and C XRD analysis of the film reveals that there can be $\mathrm{Mo}_{24} \mathrm{Cr}_{7}(\mathrm{C}, \mathrm{O})_{19}$ and $\mathrm{Cr}_{2} \mathrm{O}_{3}$ phases. The former has a crystalline structure and chemistry similar to $\mathrm{Mo}_{24} \mathrm{Cr}_{7} \mathrm{C}_{19}$. At lower temperature, the phases change to $\mathrm{Mo}_{2} \mathrm{O}_{x} \mathrm{C}_{y}$ and $\mathrm{Cr}_{3} \mathrm{C}_{2}$, which are similar to those obtained from pure molybdenum and chromium carbonyls.

The other significant aspect of the composition of the coatings from molybdenum carbonyl is shown in Table 3. The concentrations of oxygen and carbon are unequal even if these coatings are processed under similar conditions. The main reasons for the discrepancy are the unstable conditions of carbon and oxygen in the coating. The contents of $\mathrm{C}$ and $\mathrm{O}$ on the coating surface obtained between 170 to $450{ }^{\circ} \mathrm{C}$ are still in a nonequilibrium condition, and change when the surface is exposed to the atmosphere.

There are several factors which need to be considered in the variation of carbon and oxygen contents. The chromium oxycarbide has an interatomic distance $(0.293 \mathrm{~nm})$ between two neighboring $\mathrm{Cr}$ ions greater than that $(0.253 \mathrm{~nm})$ of the $\mathrm{Cr}$ ions in a close-packed structure. Therefore, $\mathrm{C}$ and $\mathrm{O}$ ions are less constrained between $\mathrm{Cr}$ cations in oxycarbide. ${ }^{32}$ The exchange of oxygen and carbon in either molybdenum or chromium carbide is strongly influenced by the oxygen content in the atmosphere.

\subsection{Microstructure of coatings}

\subsubsection{Morphologies of the coatings from the carbonyl mixture.}

Figure 9 shows a series of SEM micrographs of the surface of coated samples prepared from the carbonyl mixture at various temperatures. Surface morphologies of the coatings in low-, medium- and high-temperature regions in Fig. 9 correspond to the separate coating regions at $275^{\circ} \mathrm{C}$ and $400{ }^{\circ} \mathrm{C}$, as shown in Fig. 6. The features can be divided into two types, either 'smooth' or 'nodular' surfaces. Similar nodular morphology is observed on the coating deposited at $300^{\circ} \mathrm{C}$ and under higher pressure, 1.03-2.5 Torr. ${ }^{22}$ The pressure should not be greater than 2.5 Torr, otherwise the coated layer would crack to form domains. The formation of these cracks is due to a thermal expansion mismatch between the coated layer and the substrate.

It was reported previously, ${ }^{21}$ from observation of a side view of the thickness of the coatings, that these nodular features were formed by columnar grains. The nodules in Fig. 9(d)-9(f) are composed of very fine, but directionally grown, crystals in a preferred orientation perpendicular to the surface. A detailed comparison of the cross-sectional area (or size) of the directionally grown grains reveals that the decrease in coating temperature results in a decrease in nucleation density, and thus, in an increase in grain size. The top view of the surface morphologies of the films, i.e. Fig. 9(g) and 9(d), shows that the size of the surface nodules increases with a decrease in coating temperature from 400 to $300^{\circ} \mathrm{C}$. In the low-temperature $\left(<275^{\circ} \mathrm{C}\right)$ region, 


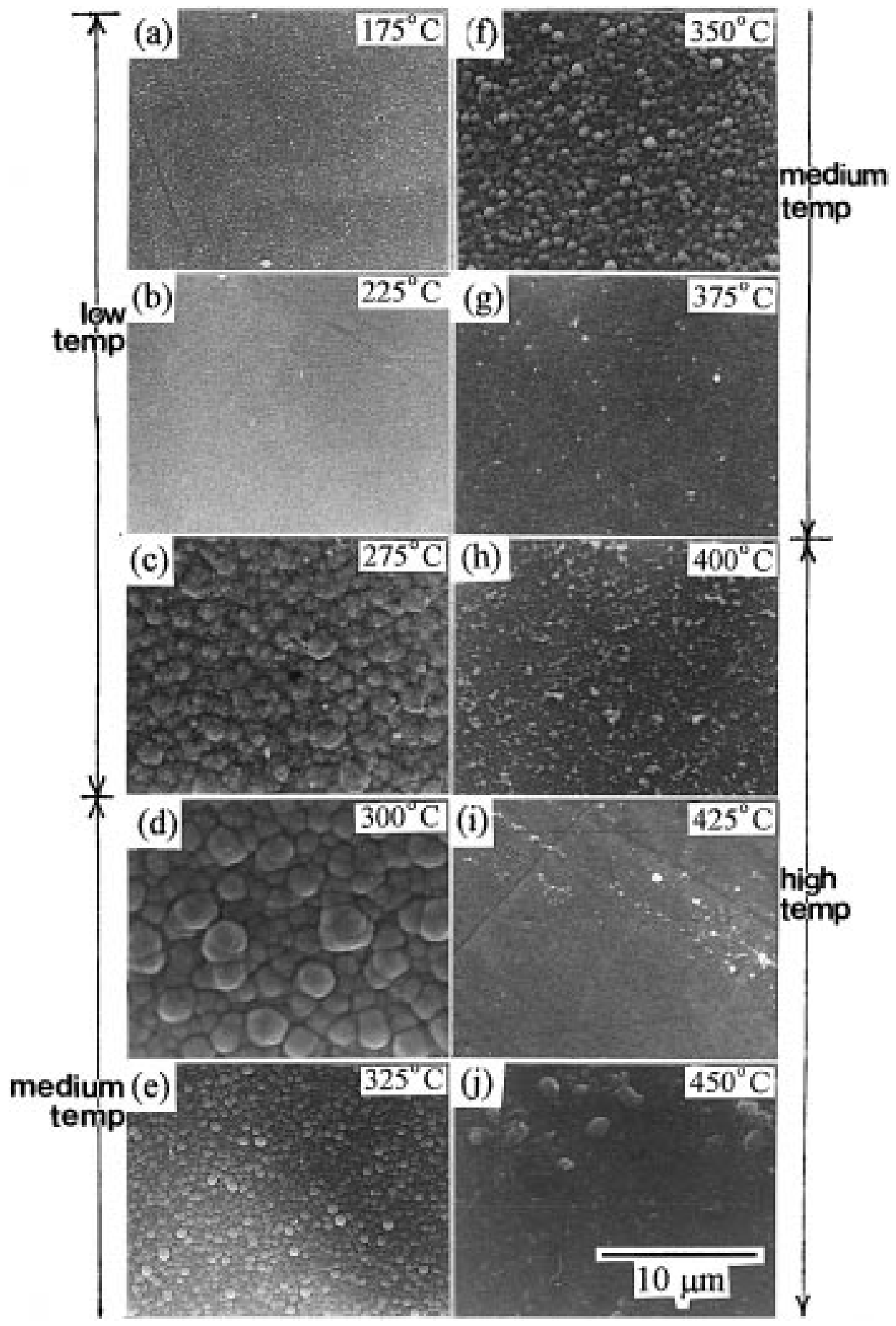

Figure 9 SEM of the surface morphologies of the coatings on SS304 from carbonyl mixtures at the indicated temperatures and at 1 Torr pressure. 
Table 3 Chemical composition (at $\%$ ) of the products prepared by decomposition of molybdenum carbonyl

\begin{tabular}{|c|c|c|c|c|c|c|c|}
\hline & \multicolumn{4}{|c|}{ Method of preparation } & & & \\
\hline & \multicolumn{4}{|c|}{ MOCVD } & \multicolumn{3}{|c|}{ LICVD } \\
\hline & \multicolumn{4}{|c|}{ Analysis technique } & \multicolumn{3}{|c|}{ Analysis technique } \\
\hline Element & $\begin{array}{c}- \\
(\text { Lander, } \\
1947)^{\mathrm{a}}\end{array}$ & $\begin{array}{l}\text { O: fusion } \\
\text { C:combust'n } \\
\text { (Ferguson, }^{\text {(Fergus }} \\
\text { 1964) }^{\mathrm{b}}\end{array}$ & $\begin{array}{c}\text { XPS } \\
(\text { Kmetz, } \\
1989)^{\mathrm{c}}\end{array}$ & $\begin{array}{c}\text { AES } \\
\left(\begin{array}{c}\text { Jackson, } \\
1989)^{\mathrm{d}}\end{array}\right.\end{array}$ & $\begin{array}{c}\text { AES } \\
\text { (Gluck, } \\
1987)^{\mathrm{e}}\end{array}$ & $\begin{array}{c}\text { O:exhalograph } \\
\text { C:combust'n } \\
\text { (Watson, }^{\text {1989) }}\end{array}$ & $\begin{array}{c}\text { AES } \\
\text { (Singmaster, } \\
1990)^{\mathrm{g}}\end{array}$ \\
\hline Mo & 62 & $57-61$ & 59 & 51 & 61 & 57 & $26-23$ \\
\hline $\mathrm{O}$ & 7 & $16-21$ & 20 & 42 & 25 & 20 & $22-24$ \\
\hline $\mathrm{C}$ & 35 & $18-27$ & 20 & 7 & 14 & 23 & $50-55$ \\
\hline
\end{tabular}

${ }^{\mathrm{a}}$ Ref. 3. ${ }^{\mathrm{b}}$ Ref. $8{ }^{\mathrm{c}}$ Ref. 9. ${ }^{\mathrm{d}}$ Ref. 40. ${ }^{\mathrm{e}}$ Ref. 6. ${ }^{\mathrm{f}}$ Ref. 31. ${ }^{\mathrm{g}}$ Ref. 30.

both the top view and side view of the coated layers, (Fig. 9a and 9c) appear very different from the layer deposited at medium and high temperatures. The surface of the sample processed at $275^{\circ} \mathrm{C}$ shows many layers of curly flakes stacked on the SS304 substrate. When the coating temperature decreases to 225 or $175^{\circ} \mathrm{C}$, the coatings (Figs 9a and 9b) change to a smooth surface.

Elemental distributions of one high-temperature coating across the thickness are shown in Fig. 10. Four elements (Mo, Cr, Fe and $\mathrm{O}$ ) were analyzed by EPMA. The full scales of the compositional intensities are not equal for these four elements. Mo contents in SS304 and the coating are barely detectable. $\mathrm{Cr}$ and $\mathrm{Fe}$ can be found in SS304, which contains mainly a $\mathrm{Cr}_{0.19} \mathrm{Fe}_{0.7} \mathrm{Ni}_{0.11}$ phase; some concentration intensities of these elements are also evident in the coating. The source of $\mathrm{Cr}$ could be the deposition of pyrolyzed chromium carbonyl, but $\mathrm{Fe}$ can only be supplied (diffused) from the interface of SS304. The result in Table 2 shows that only a carbon solid solution of $\mathrm{Cr}_{2} \mathrm{O}_{3}$ phase is detected, which is consistent with the XPS analysis in Fig. 8. However, a detailed microstructural analysis by TEM shown in Fig. 11 indicates that a thin intermediate layer with a spinel structure is formed between SS304 and $\mathrm{Cr}_{2} \mathrm{O}_{3}$. The bright-field image (Fig. 11a) is taken from the combination of

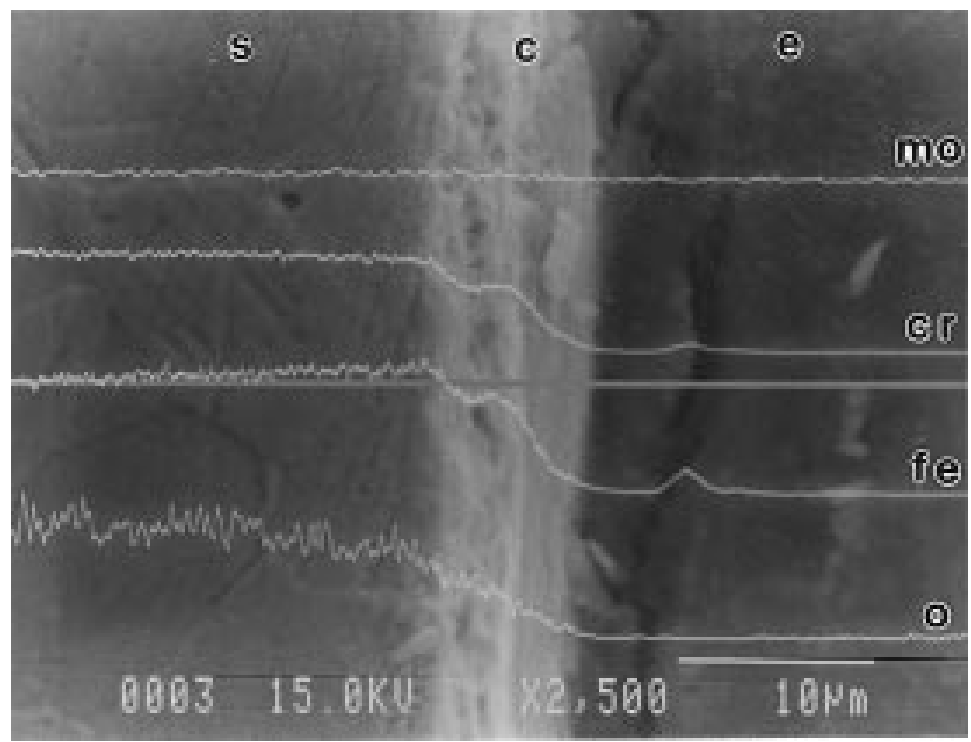

Figure 10 EPMA line scans of $\mathrm{Mo}_{2}, \mathrm{Cr}, \mathrm{Fe}$ and $\mathrm{O}$ on the cross-section of the coating on SS304 from carbonyl mixtures processed at high temperatures: s, substrate; c, coating layer; e, epoxy. 

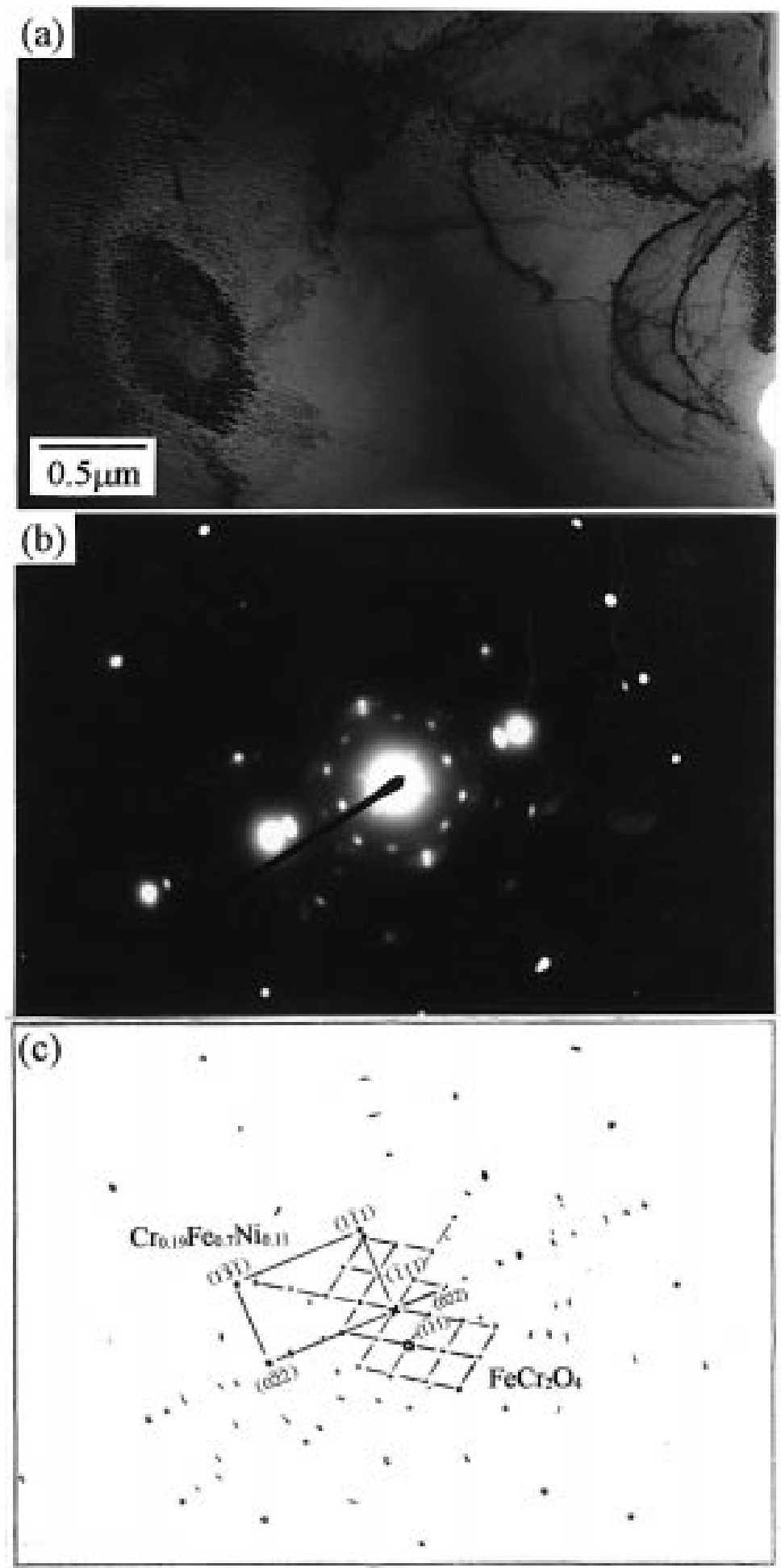

Figure 11 (a) TEM bright-field micrograph, (b) diffraction pattern, and (c) schematic diffraction pattern with indexing of matrix steel and spinel $\mathrm{FeCr}_{2} \mathrm{O}_{4}$ phases. 
Table 4 Corrosion resistance, hardness and adhesive strength of the coatings processed under various conditions

\begin{tabular}{|c|c|c|c|c|}
\hline \multirow[b]{3}{*}{ Property } & \multicolumn{4}{|c|}{ Coating } \\
\hline & \multirow{2}{*}{$\begin{array}{c}\text { SS304 } \\
\text { substrate }\end{array}$} & \multicolumn{3}{|c|}{ Processing temperature } \\
\hline & & Low & Medium & High \\
\hline $\begin{array}{l}\text { Corrosion } \\
\text { resistance }\end{array}$ & Poor & Good & Best & Poor \\
\hline Hardness & $1.73 \mathrm{GPa}$ & $\begin{array}{c}\text { Good } \\
(8.61 \mathrm{GPa})\end{array}$ & $\begin{array}{c}\text { Fair } \\
(2.75 \mathrm{GPa})\end{array}$ & $\begin{array}{c}\text { Poor (less } \\
\text { than SS) }\end{array}$ \\
\hline $\begin{array}{l}\text { Adhesion } \\
\text { strength }\end{array}$ & - & $\begin{array}{l}\text { Poor } \\
(2.8 \mathrm{~N})\end{array}$ & $\begin{array}{l}\text { Good } \\
(37.6 \mathrm{~N})\end{array}$ & $\begin{array}{c}\text { Good } \\
(36.0 \mathrm{~N})\end{array}$ \\
\hline
\end{tabular}

$\mathrm{Cr}_{0.19} \mathrm{Fe}_{0.7} \mathrm{Ni}_{0.11}$ grains and possibly an $\mathrm{FeCr}_{2} \mathrm{O}_{4}$ spinel phase. The diffraction pattern (Fig. 11b) and the indexed diffraction pattern (Fig. 11c) reveal the orientation relationship between these two phases to be $(022)_{\text {spinel }} / /(0 \overline{22})_{\text {steel }}$ and $(\overline{111})_{\text {spinel }} / /(1 \overline{11})_{\text {steel }}$. The formation kinetics of this spinel phase have not been investigated, but could be the result of heat treatment at $400{ }^{\circ} \mathrm{C}$, inducing the interaction of $\mathrm{Fe}$ with $\mathrm{Cr}_{2} \mathrm{O}_{3}$. The existence of the $\mathrm{Fe}-\mathrm{Cr}$-spinel phase might be responsible for a better adhesive strength of the coatings prepared at medium and high temperatures (Table 4).

Figure 12(a) is a high-resolution TEM micrograph; Fig. 12(b) shows an electron diffraction pattern of the coating on SS304 from the carbonyl mixture prepared at high $\left(>400{ }^{\circ} \mathrm{C}\right)$ temperature. The high-resolution microstructure shows periodic atomic domains, which are pointed out by arrowheads in the micrograph, to be $\mathrm{Mo}_{2} \mathrm{O}_{x} \mathrm{C}_{y}$ crystals about $2.5 \mathrm{~nm}$ in size. Figure 12 (b) reveals that the other phase, chromium carbide, is also detected in the matrix. This agrees with the phases reported from the XRD results (Table 2).

\subsubsection{Morphologies of the coatings on $\mathrm{SS304}$ from pure $\mathrm{Mo}(\mathrm{CO})_{6}$ or $\mathrm{Cr}(\mathrm{CO})_{6}$}

Two series of SEM micrographs of the coating from either pure $\mathrm{Mo}(\mathrm{CO})_{6}$ or $\mathrm{Cr}(\mathrm{CO})_{6}$ are shown in Fig. 13 and Fig. 14. No apparent feature is noted in the

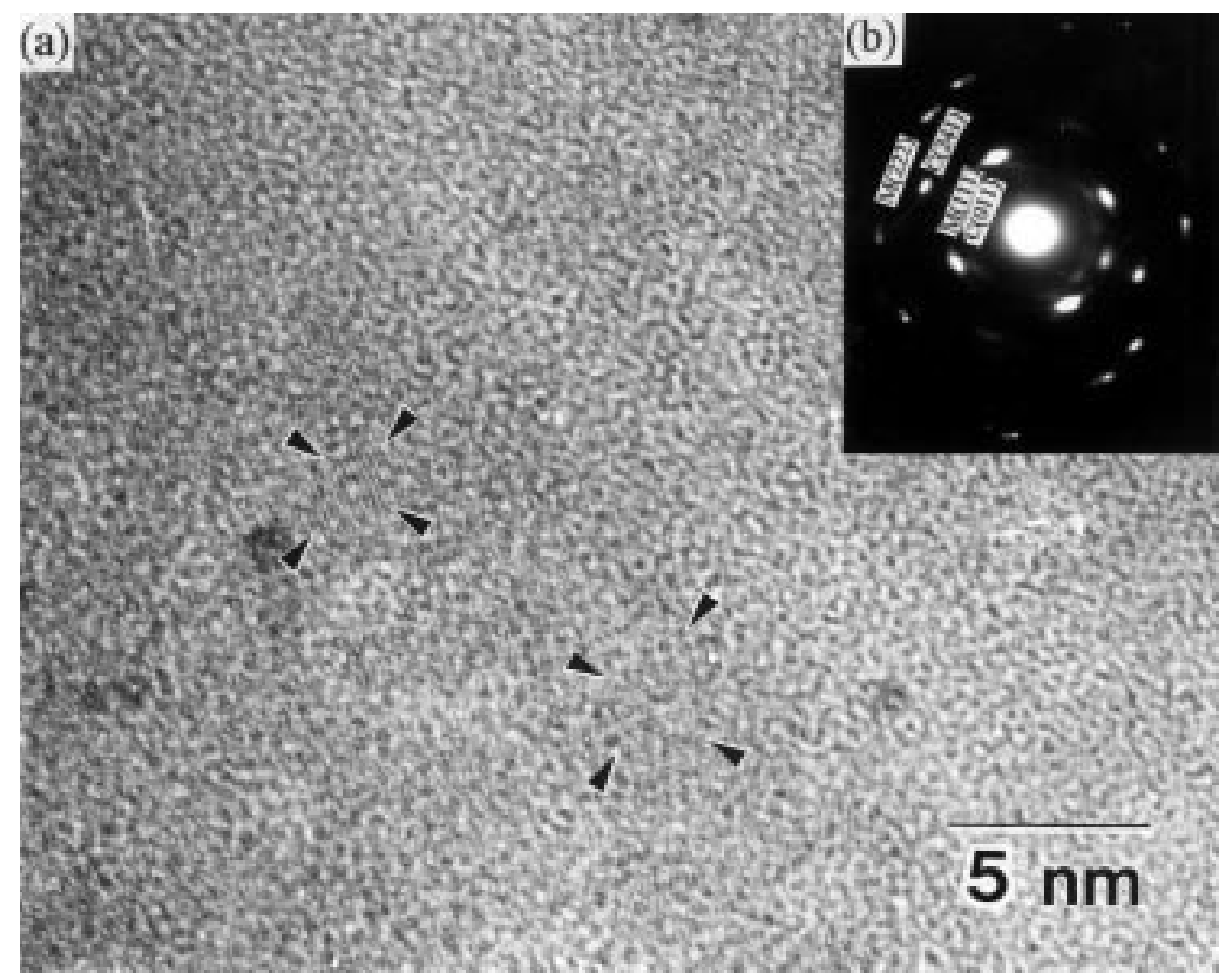

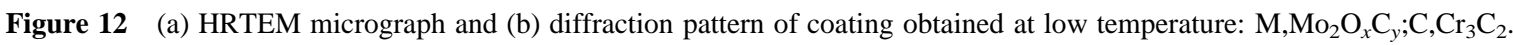



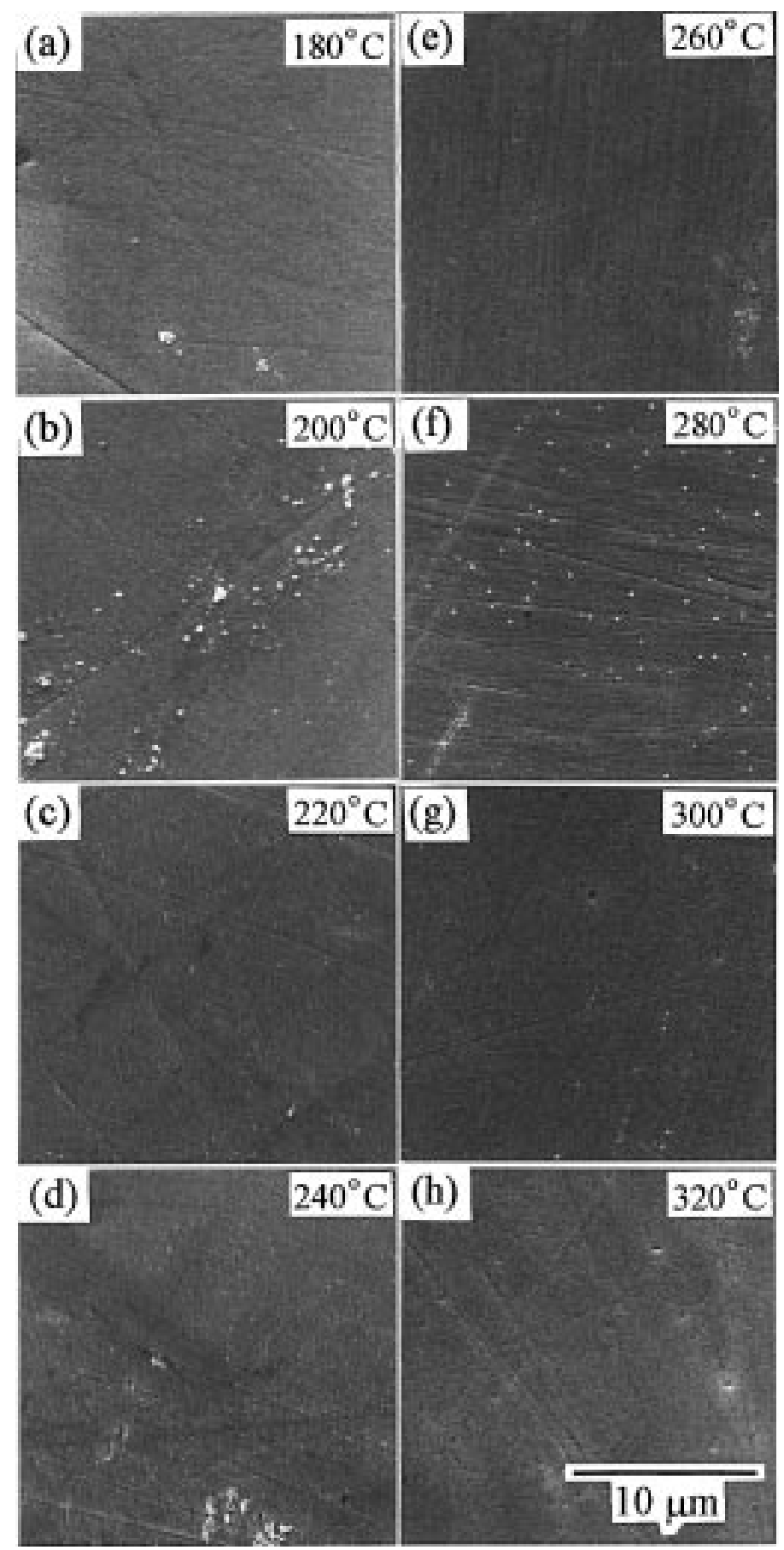

Figure 13 SEM of the surface morphologies of the coatings on SS304 from pure $\mathrm{Mo}(\mathrm{CO})_{6}$ at the indicated temperature and at 1 Torr pressure. 
former case, which shows merely a flat surface in a $\mathrm{Mo}_{2} \mathrm{O}_{x} \mathrm{C}_{y}$ phase (Table 2). The causes for the difference in the deposited thickness of the $\mathrm{Mo}_{2} \mathrm{O}_{x} \mathrm{C}_{y}$ coating could not be a variation in the types of controlling reaction; but the deposition rate could have been adjusted by surface reactions and by the temperature.

The surface prepared from chromium carbonyl is incorporated entirely with the $\mathrm{Cr}_{3} \mathrm{C}_{2}$ phase. However, the morphology (Fig. 14) of the $\mathrm{Cr}_{3} \mathrm{C}_{2}$ consists of small nodules, each nodule being a well-crystallized chromium carbide grain. It is also noted that bright spots in the micrographs are less than $1 \mu \mathrm{m}$ in size, and could be a chemically enriched region, most probably chromium rich grains.

\subsection{Corrosive and mechanical properties of coatings on SS304}

\subsubsection{Corrosive protection from acid}

Corrosion resistance can be evaluated either by analyzing the weight loss in a long-term test or by measuring the current density of corrosive pieces. ${ }^{33}$ The latter method is currently accepted; from the corrosion current, curves, two key parameters, corrosion current $\left(i_{0}\right)$ equilibrium potential $\left(E_{0}\right)$, are obtained. The smaller the value of $i_{0}$ and the higher the current for breaking the protective (inert) layer, the better is the corrosion resistance.

It is reported that the electric current density of the coating obtained at low or medium temperatures is smaller than that of SS304. The corrosion resistance improvement factor in the presence of oxycarbide films is about 24-fold. The absolute value of the current density, $2.1 \times 10^{-5} \mu \mathrm{A} \mathrm{cm}^{-2}$, for a polished SS304 plate is much smaller than the value of $2.0 \mu \mathrm{A} \mathrm{cm}^{-2}$ for as-sintered $\mathrm{SS} 304^{23}$ whereas the current density of the sample obtained at a high temperature $\left(450^{\circ} \mathrm{C}\right)$ is larger than that of the SS304 substrate. It was reported in Section 5.1 that the protective oxide layer basically formed on the stainless steel is dense, whereas the film formed from the process at temperatures greater than $400{ }^{\circ} \mathrm{C}$ is porous. Inappropriate coating by MOCVD results in a degradation of the corrosion resistance of the SS304 plate by a factor of 28fold. ${ }^{21}$ Further investigation of the potentiodynamic scan curve reveals that only the film prepared at a medium temperature on the SS304 plate possesses passive protection. The current density of passive corrosion of the coating is $10 \mu \mathrm{A} \mathrm{cm}^{-2}$. The results indicate that the film coated at a medium temperature is the best candidate for the improvement of corrosion resistance of stainless steel in the environment with chloride and sulfuric acids, as indicated in Table 4.

The corrosive protection of the (Mo,Cr) oxycarbide films by MOCVD is strongly correlated with the crystalline phases and the intactness of the films, since the corrosion resistance of stainless steel can be due to the formation of a protective chromium oxide layer. Improvement of the most protective oxycarbide film should, therefore, be produced by either the protection of $(\mathrm{Mo}, \mathrm{Cr})$ oxycarbides, which might perform similar protection mechanisms to those reported by Weil and $\mathrm{Sheu}^{34}$. It was demonstrated that films with either $\mathrm{Cr}+\mathrm{Mo}$ or $\mathrm{Cr}+\mathrm{C}$ content had superior or better corrosion resistance, respectively, than that of the single-layer chromium coatings for the corrosion of sulfuric acid. The films prepared by Weil and Sheu were possibly oxidized. Similar conditions appear in the coatings that contain two solid-solution phases, $(\mathrm{Mo}, \mathrm{Cr})_{2}(\mathrm{C}, \mathrm{O})_{3}$ and $\mathrm{Mo}_{24} \mathrm{Cr}_{7}(\mathrm{C}, \mathrm{O})_{19}$, which have the best protective properties like those seen in Weil's.

\subsubsection{Hardness of coating layers}

One of the applications of (Mo, Cr) oxycarbide coatings is to improve the surface hardness of soft substrates. Micro-indentation techniques were used to evaluate the real hardness of a thin surface layer. ${ }^{35,36}$ One indirect method has been proposed by Thomas $^{37}$ using Vickers indentation with various loads; the hardness of the films can then be calculated. The results are shown in Table 4; the coating at the temperature above $400{ }^{\circ} \mathrm{C}$ was too soft to be detected by the indentation, but otherwise, the hardness of these films from medium- and low-temperature coatings was determined to be 5 and 1.6 times higher, respectively, than the SS304 substrate.

\subsubsection{Adhesion of coating to substrate}

Adhesive forces can be chemical bonding or physical interlocking to combine two neighboring faces. The scratch test is one of the evaluation methods often reported in the literature. ${ }^{38}$ The test utilizes a piezo-electric detector for acoustic emission and can determine the critical fracture force as the coating detaches. The best value among three (Mo, Cr) oxycarbide coatings is $37.6 \mathrm{~N}$, which is considered as good as the adhesive strength $(38 \mathrm{~N})$ of TiN film on tooling steel prepared by Bull et al. ${ }^{39}$ In fact, the good adhesive property of the coatings obtained at medium and high temperatures (Table 4) is partly due to the presence of the $\mathrm{Fe}-\mathrm{Cr}-$ 

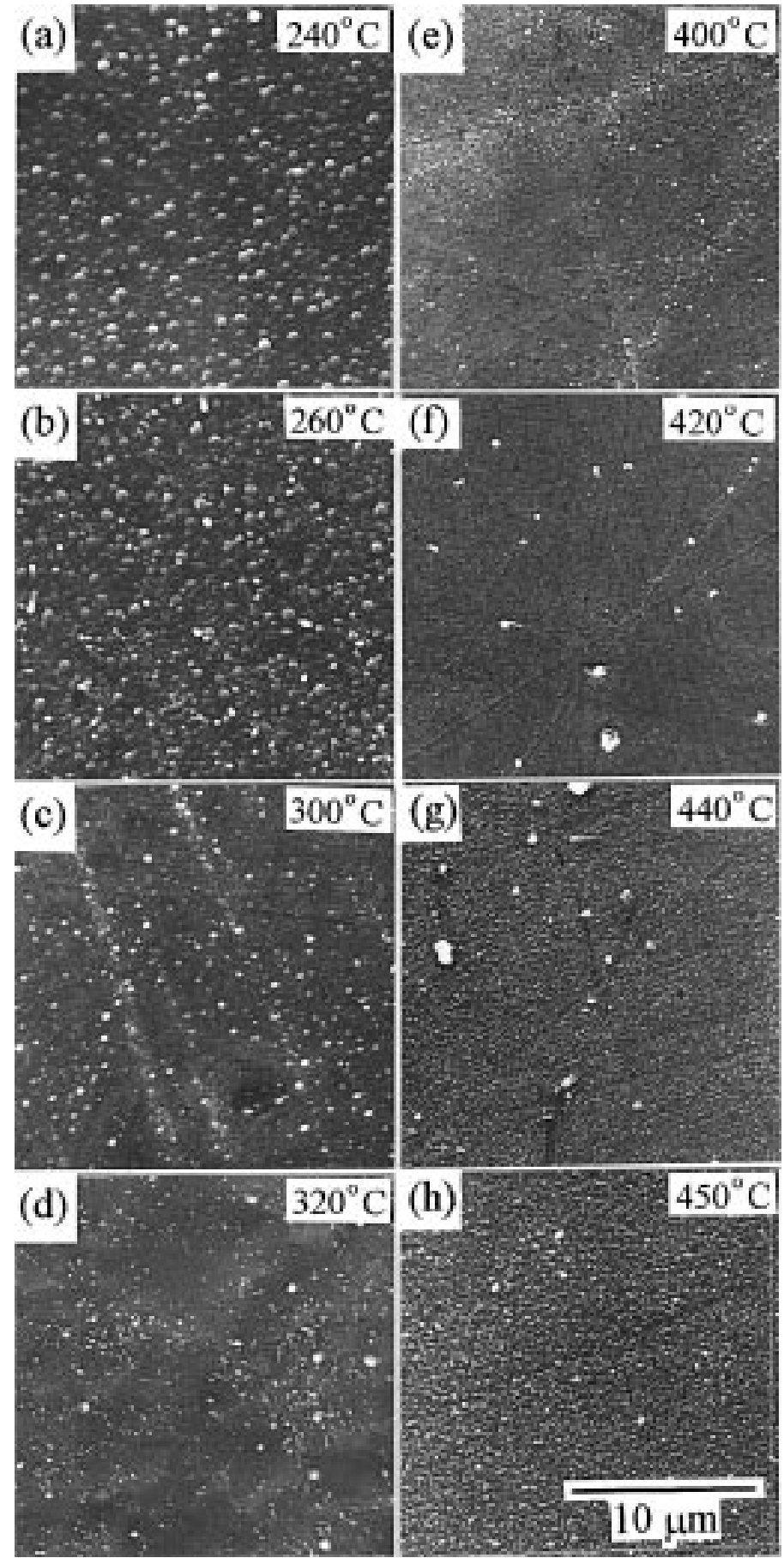

Figure 14 SEM of the surface morphologies of the coatings on SS304 from pure $\mathrm{Cr}(\mathrm{CO})_{6}$ at the indicated temperatures and at 1 Torr pressure. 
spinel phase (Fig. 11). An intermediate spinel layer formed by diffusion gives a strong bonding beneficial in holding the thin film on a stainless steel substrate.

\section{CONCLUSION}

Films prepared at $175-450^{\circ} \mathrm{C}$ by the MOCVD process from the hexacarbonyls of chromium, molybdenum or their mixture, and the related kinetics of deposition processes, were reviewed and studied. Considering the kinetics of the deposition steps, evaporation, diffusion and pyrolysis of the carbonyls, and also the reactions occurring on the surface of SS304 and SiC, the measured data of the coating rates strongly suggest that the deposition is controlled by an exothermic surface reaction. The catalytic effects of $\mathrm{Cr}$ in the gaseous phase and the SS304 substrate could be the reasons for the transitions in the coating rate, composition and deposited phases of the coatings in various temperature regions.

Phase analyses show that the films obtained in medium-temperature regions contain $\mathrm{Cr}_{2}(\mathrm{C}, \mathrm{O})_{3}$ and $\mathrm{Mo}_{24} \mathrm{Cr}_{7}(\mathrm{C}, \mathrm{O})_{19}$, but $\mathrm{Mo}_{2} \mathrm{O}_{x} \mathrm{C}_{y}$ and $\mathrm{Cr}_{3} \mathrm{C}_{2}$ are present in the coatings formed at lower temperature. The films from low and medium temperatures greatly improved the corrosion resistance of SS304. The film which consists of a porous $\mathrm{Cr}_{2} \mathrm{O}_{3}$ phase, obtained at high temperature, is the most inferior among these coatings. The best film is obtained from deposition at medium temperature, performing passive protection and providing an improvement on acidic corrosion resistance.

Improvements of corrosion resistance, hardness and adhesive strength for stainless steel by the oxycarbide films formed at various temperatures were reviewed. The hardness of both coatings, either at low or medium temperature, was greater than that of the SS substrate, but the coating processed at a high temperature was softer than the substrate. Adhesive strengths of the coatings from medium and high temperatures were $38 \mathrm{~N}$ and $36 \mathrm{~N}$, respectively, showing a better bonding state than that $(2.8 \mathrm{~N})$ obtained at low temperature.

Acknowledgments The authors acknowledge the research funding given by National Science Council (NSC) in Taiwan under contract No. NSC85-2216-E-002-019.

\section{REFERENCES}

1. D. S. Rickerby and A. Matthews, Advanced Surface Coatings: A Handbook of Surface Engineering, Chapman and Hall, New York, 1991.

2. R. A. Miller, Surf. Coat. Technol 30, 1 (1987).

3. J. J. Lander and L. H. Germer, Plating Molybdenum, Tungsten and Chromium by Thermal Decomposition of Their Carbonyls, Am. Inst. Min. Metal. Eng. Tech. Pub. No. 2295, Sept 1947.

4. F. Okuyama and Y. Fujimoto, J. Appl. Phys. 56566 (1984).

5. V. L. Podopprigora and A. K. Baev, Primen. Metalloorg. Soedin. Poluch. Neorg. Pokrytii Mater. 76 (1986).

6. N. S. Gluck, G. J. Wolga, C. E. Bartosch, W. Ho and Z. Ying, J. Appl. Phys. 61998 (1987).

7. G. B. Stringfellow, Approximate analytical approach for OMVPE reactor. In: Organometallic Vapor-Phase Epitaxy, Theory and Practice, Academic Press, New York 1989, pp. 226-230.

8. I. F. Ferguson, J. B. Hinseough, D. Morse and A. W. Miller, Nature (London) 2021327 (1964).

9. M. Kmetz, S. L. Suib and F. S. Galasso, J. Am. Ceram. Soc. 72, 1523 (1989)

10. S. M. Rossnagel, in: Thin Film Process, 2nd edn, Vossen, J. L. and Kern, W. (eds), Academic Press, Orlando, 1991.

11. D. E. Sherwood Jr and M. B. Hall, Inorg. Chem. 22, 93 (1983).

12. T. Ziegler, V. Tschinke and C. Ursenbach, J. Am. Chem. Soc. 109, 4825 (1987).

13. A. Nilsson, N. Maartensson, S. Svensson, L. Karsson and D. Nordfors, J. Chem. Phys. 96, 8770 (1992).

14. A. K. Baev, Zh. Fiz. Khim. 67, 1607 (1993).

15. A. K. Baev, Zh. Obshch. Khim. 64, 212 (1994).

16. A. K. Baev and V. P. Krselevich, Kinet. Katal. 33, 828 (1992).

17. A. K. Baev and V. P. Krselevich, Zh. Obshch. Khim. 62, 537 (1992).

18. A. K. Baev and V. P. Krselevich, Zh. Fiz. Khim. 68, 93 (1994).

19. A. K. Baev, Izv. Vyssh. Uchebn. Zaved., Khim. Khim. Tekhnol., 36, 40 (1993).

20. E. N. Fuller, P. D. Schettler and J. C. Giddings, Ind. Eng. Chem. 58, 19 (May 1996).

21. M.-H. Lo and W.-C. J. Wei, J. Am. Ceram. Soc., 80, 886 (1997)

22. M.-H. Lo, Ph.D. Dissertation, National Taiwan University, 1996.

23. A. J. Sedriks, in: Corrosion of Stainless Steel, John Wiley, New York, 1979.

24. A. W. Vere, in: Crystal Growth: Principle and Progress, Plenum Press, New York 1987, Chapter 2.

25. T. Kaito and T. Adachi, Europ. Pat. Appl. EP 247714 (1986).

26. D. K. Flynn, J. I. Steinfeld and D. S. Sethi, J. Appl. Phys. 59, 3914 (1986).

27. S. L. T. Andersson and R. F. Howe, J. Phys. Chem. 93, 4913 (1989).

28. S. R. Nutt and F. E. Warner, Ceram. Eng. Sci. Proc. 2, 840 (1981).

Appl. Organometal. Chem. 12, 201-220 (1998) 
29. K. A. Gesheva, T. A. Krisov, U. I. Simkov and G. D. Beshkov, Appl. Surf. Sci. 73, 86 (1993).

30. K. A. Singmaster, F. A. Houle and R. J. Wilson, J. Phys. Chem. 94, 6864 (1990).

31. I. M. Watson, J. A. Connor and R. Whyman, Polyhedron 8 , 1794 (1989).

32. L. E. Toth, in: Transition Metal Carbides and Nitrides, Academic Press, New York, 1971, pp. 31-46, 79-85.

33. H. H. Uhlig and R. W. Revie, in: Corrosion and Corrosion Control, 3rd edn, John Wiley \& Sons, Inc., New York, 1985, p. 78.

34. R. Weil and C. Sheu, Properties of Composite Electro-
Deposits, Final Report, Army Research Office, July 1987Aug. 1990, Research Triangle Park, NC, USA, 1990.

35. D. S. Rickerby and P. J. Burnett, Thin Solid Films 57, 195 (1988).

36. M. H. Lo and W. J. Wei, J. Mater. Res. 11, 2895 (1996).

37. A. Thomas, Surf. Eng. 3, 117 (1987).

38. D. S. Rickerby, Surf. Coat. Technol., 36, 541 (1988).

39. S. J. Bull, D. S. Rickerby, A. Matthews, A. Leyland and A. R. Pace, Surf. Coat. Technol. 36, 503 (1988).

40. R. L. Jackson, G. W. Tyndall and S. D. Sather, Appl. Surf. Sci. 36, 119 (1989). 